\title{
8 Medien- und ausdruckstheoretischer Bezugspunkt: Ausdruck, Wahrnehmung, Verkörperung und audiovisuelle Bilder
}

\subsection{Medialität im Sinne aisthetischer Performativität (Krämer)}

Es sei sich zunächst der jüngeren Performativitätsforschung, ${ }^{1}$ genauer: dem Konzept aisthetischer Performativität zugewandt, das darauf zielt, ,eine Dimension aller kulturellen Praktiken im Spannungsverhältnis zwischen einem Ereignis und seiner Wahrnehmung“ zu erfassen. ${ }^{2}$ Was kann dieses Konzept für das Vorhaben leisten, eine Idee situativ entstehender, verkörperter und dynamischer Bedeutung im Sinne eines filmischen Metaphorisierens entfalten zu wollen? Mit seiner korporalisierenden Performativitätskonzeption als Gravitationszentrum ${ }^{3}$ impliziert dieses Konzept einen Vorschlag, wie sich Medialität anders als vom Moment des Transfers oder der Repräsentation her denken lässt. Eben dies wurde ja als ein

1 Ihren Anfang findet die Performativitätstheorie in den 1960er Jahre in Austins Sprechakttheorie (John Langshaw Austin: Zur Theorie der Sprechakte [1962]. Stuttgart: Reclam 1979). Das Performative ist ein Begriff, der alsbald nicht nur in sprach- und kommunikationstheoretischen Überlegungen einen prominenten Platz einnimmt, denn auch Kultur- und Kunst- und Medientheorien eignen sich den Gedanken an, und so erscheinen die Forschungen zum Performativen bis heute sehr vielgestaltig. Nicht zuletzt der kleinste gemeinsame Nenner der Akteure dieser Performativitätsdebatte, nämlich ihre repräsentationskritische Haltung ist es, die jenen Forschungsansatz für die vorliegende Arbeit relevant macht. Geht es doch, wie bereits angemerkt, darum, das audiovisuelle Bild weniger als eine Repräsentation vorgängiger Wirklichkeit in den Blick zu bekommen, als vielmehr als eine Produktion von Welt durch die Hervorbringung eines Denkens in Bildern und Tönen, in Bewegungsbildern.

2 Sybille Krämer: Was haben ,Performativität‘ und ,Medialität‘ miteinander zu tun? Plädoyer für eine in der Aisthetisierung gründende Konzeption des Performativen. Zur Einführung in diesen Band. In: Performativität und Medialität. Hrsg. v. Sybille Krämer. München: Wilhelm Fink 2004, S. 13-32, hier S. 21, Herv. i. O. Im Folgenden wird sich vor allem auf die Ausführungen hierzu von Krämer konzentriert werden. Vgl. zur aisthetischen Performativität auch Dieter Mersch: Ereignis und Aura. Untersuchungen zu einer Ästhetik des Performativen. Frankfurt a. M.: Suhrkamp 2002.

3 Prägend für die korporalisierende Performativitätskonzeption sind etwa die Arbeiten von Fischer-Lichte (Erika Fischer-Lichte: Ästhetik des Performativen. Frankfurt a. M.: Suhrkamp 2004). Andere charakteristische Gravitationszentren der Performativitätsdebatte, die je mit einer anderen Stoßrichtung der Repräsentationskritik einhergehen, wären eine „universalisierende“ Performativitätskonzeption - etwa bei Habermas (Jürgen Habermas: Vorstudien und Ergänzungen zur Theorie des kommunikativen Handelns. Frankfurt a. M.: Suhrkamp 1984) - und eine ,iterabilisierende“ Konzeption - etwa bei Butler (Judith Butler: Körper von Gewicht. Die diskursiven Grenzen des Geschlechts [1993]. Berlin: Berlin-Verlag 1995). Vgl. Krämer: Was haben ,Performativität‘ und ,Medialität‘ miteinander zu tun?, S. 14-19.

Ә Open Access. (๑) 2020 Christina Schmitt, publiziert von De Gruyter. (c) BY-NC-ND Dieses Werk ist lizenziert unter der Creative Commons Attribution-NonCommercial-NoDerivatives 4.0 Lizenz. https://doi.org/10.1515/9783110614619-008 
zentrales Problem bei den auf der KMT aufbauenden Ansätzen zur Metapher im Kontext audiovisueller Bilder identifiziert. ${ }^{4}$ Der Vorschlag, den die aisthetische Performativität nun macht, ist, das Mediale vom Konstruktiv-Konstitutiven, vom Hervorbringen von Welt her zu denken. Denn unter Berücksichtigung von Wahrnehmung im Sinne von Aisthesis ${ }^{5}$ rückt für die Performativitätstheorie der „Prozess der sinnlichen Wahrnehmung“, soweit dieser durch den betrachteten Gegenstand (ob nun aus dem Bereich der Kunst oder aber des Alltags) „selbst sinnfällig wird“, in den Fokus: „Die Aufmerksamkeit wird vom Lesen zeichenhafter Bedeutungen auf den prozessualen Vollzug der Wahrnehmung im Angesicht der Kunst (und darüber hinaus)“ gelenkt. Auf diese Weise lässt das Konzept aisthetischer Performativität das Zwei-Welten-Modell hinter sich. Und Oberflächen werden als ein ,in-Szene-setzendes Wahrnehmbarmachen“ in den Blick genommen. ${ }^{6}$

,Aisthetische Performativität‘ adressiert einen Wahrnehmungsakt, der über zwei Pole verfügt, die miteinander in Beziehung stehen. Im Zentrum des Interesses steht ein Wahrnehmungsgeschehen, das sich zwischen einem Ereignis und der Wahrnehmung dieses Ereignisses, zwischen einem Akteur und seinem Zuschauer aufspannt, und das „mithin zwischen Machen und Rezipieren“ angelegt ist. ${ }^{7}$ Die Möglichkeit zu einer solchen „Wechselbeziehung von Hervorbringen und Empfangen“, zu einem „,Austausch“ zwischen Akteur und Zuschauer“ begründet sich, so Sybille Krämer, dabei weniger durch den Bezug auf ein gemeinsames System. Vielmehr spielt eine konkrete Korporalität für Austausch und Wechselbeziehung die zentrale Rolle: „eine Korporalität, welche die Körperlichkeit von Menschen, Dingen und Zeichen im Spektrum eines Materialitätskontinuums gleichermaßen umfasst“. 8

Ein aisthetisch ausgerichtetes Performativitätskonzept zielt damit auf eine „Vollzugs- und Handlungsdimension“, die „als Voraussetzung und Kehrseite [...] kommunikative[r] und semiotische[r] Prozesse" betrachtet wird. ${ }^{9}$ Daher werden Wahrnehmung und Vollzug also gerade „nicht gegen die Möglichkeit sinnhafter Signifikanz“ ausgespielt, vielmehr wird „auf der fundierenden Rolle aisthetischer

4 Vgl. Kapitel 3-5 der vorliegenden Arbeit.

5 Vgl. neben Welsch: Aisthesis auch Gernot Böhme: Aisthetik. Vorlesungen über Ästhetik als allgemeine Wahrnehmungslehre. München: Wilhelm Fink 2001; Martin Seel: Ästhetik des Erscheinens. Wien: Hanser 2000.

6 Krämer: Was haben ,Performativität‘ und ,Medialität‘ miteinander zu tun?, S. 25.

7 Ebd., S. 21, Herv. i. O.

8 Ebd.

9 Thomas Morsch: Wahrgenommene Wahrnehmung, gesehenes Sehen. Zur aisthetischen Performativität des Films. In: Kunstkommunikation. „Wie ist Kunst möglich?“ Beiträge zu einer systemischen Medien- und Kunstwissenschaft. Hrsg. v. Christian Filk und Holger Simon. Berlin: Kulturverlag Kadmos 2010, S. 251-266, hier S. 260 f., Herv. i. O. 
und pragmatischer Handlungsvollzüge für die Genese von Bedeutung beharrt“. ${ }^{10}$ Medien werden daher auch nicht marginalisiert, denn gerade durch sie realisiert sich ein „in-Szene-setzendes Wahrnehmbarmachen“. Es ist dies ein Wahrnehmbarmachen, ein In-Szene-Setzen, das „immer das einmalige Ereignis einer Gegenwärtigkeit [ist], das sich an genau dieser singulären Raum-Zeit-Stelle vollzieht“. ${ }^{11}$

Medien vermitteln denn auch nicht einfach Sinn und Bedeutung, wie Krämer hervorhebt. Sie generieren dies vielmehr, eben indem sie „phänomenalisieren“, d. h. „wahrnehmbar machen“. ${ }^{12}$ Dabei wirken sie „nicht durch Symbolisierung, sondern durch ,Somatisierung،, indem sie also verkörpern“ - und das, was sie verkörpern, die Bedeutung, die sie generieren, „ist keine mehr oder weniger stabile Entität, sondern existiert nur in der flüchtigen und prozessualen Gegenwärtigkeit des Medienumgangs“. ${ }^{13}$ Von Medien als Vermittlern zu sprechen, ist demnach nicht im Sinne eines technischen Instruments gemeint. Und es setzt sich auch ab vom semiotischen Organon - zumindest, wenn dies, wie bei Bühlers Ausgangstheorie der Fall (und anders als bei Müller etwa, wie weiter oben ausgeführt), wesentlich auf einer Idee des Symbols, des arbiträren Zeichens aufbaut. Aus Perspektive der aisthetischen Performativität findet sich das Vermittelnde von Medien vielmehr darin, dass sie als ,Mitte‘ und ,Mittleres ‘ in einer verkörpernden Weise gegenwärtig sind - "zwischen zwei Polen oder Positionen, zwischen denen sie ein Sinnlichkeitskontinuum stiften“. ${ }^{14}$ Genau im Phänomenalisieren, im Wahrnehmbarmachen liegt hier das Verständnis von Verkörperung. Dementsprechend adressiert Verkörperung nicht neurologische Prozesse, und Verkörperung ist auch

nicht als Leibapriori im Sinne einer vorgängigen Körperlichkeit zu verstehen, sondern als Frage nach der Materialität, nach den ,stummen', den vorprädikativen Formgebungen von Sinn. ,Verkörperung، kennzeichnet die Nahtstelle der Entstehung von Sinn aus nicht-sinnhaften Phänomenen ${ }^{15}$

- und zwar bezogen auf jeweils konkrete Situationen, d. h. bezogen auf eine flüchtige und prozessuale Gegenwärtigkeit (bzw. das Ereignis) eines Medienum-

10 Ebd., S. 261.

11 Krämer: Was haben ,Performativität‘ und ,Medialität‘ miteinander zu tun?, S. 21. Dass es sich dabei zugleich „um ein durch einen Akteur hervorgebrachtes Wahrnehmungsgeschehen handelt, in das Elemente sowohl des Reproduktiven wie Planvollen verwoben sind“, steht hierzu nicht im Widerspruch (ebd.)

12 Ebd., S. 25.

13 Ebd.

14 Ebd.

15 Krämer: Sprache - Stimme - Schrift, S. 345. 
gangs, eines Mediengebrauchs. Das Ästhetische wird dabei in hervorgehobener Weise als Feld angesehen, in dem ,alle Prozesse der Sinnstiftung und der Konstitution von Bedeutung im besonderen Maße an den Körper gebunden“ sind, weshalb auch „die Sensualität von Kunstwerken und ihre Intellektualität“ zusammenfallen. ${ }^{16}$

Somit „zielt der Leitbegriff der ,Verkörperung““ hier darauf, in den Blick zu bekommen, ,,wie etwas gemacht wird“ oder ,wie etwas für uns gegeben ist“““. ${ }^{17}$ Und insofern werden durch einen solchen (im weitesten Sinne kulturwissenschaftlichen) Verkörperungsbegriff Oberflächen fokussiert. Denn, so spitzen es Helmuth Feilke und Angelika Linke in ihrer Einleitung zu Oberfläche und Performanz zu: Fragen nach dem ,Wie“ „sind immer Oberflächenfragen“. ${ }^{18}$ Anstatt allerdings Oberflächen im Rahmen eines Zwei-Welten-Modells zu betrachten, interessiert an ihnen dann, wie eine „Ausdrucksgestalt, die Inhalt und Form integriert“, in Erscheinung tritt. ${ }^{19}$

Auf einer Metaebene betrachtet, deuten die vorangegangenen Darlegungen schließlich darauf hin, dass ,aisthetische Performativität‘ ein Konzept mit transgressivem Charakter ist, woraus nicht zuletzt für das Beschreiben jener Dimension kultureller Praktiken gewisse Herausforderungen erwachsen. Denn aisthetische Performativität betrifft einen „Vollzug, in dessen Beschreibung dichotomisch organisierte Begriffsraster“ - etwa die kategorische Unterscheidung zwischen einem Kunstobjekt und seinem Betrachter, oder zwischen Form und Inhalt - „an ihre Grenzen stoßen“. ${ }^{20}$

Vor diesem noch allgemein gehaltenen medienphilosophischen Hintergrund sei nun mit der phänomenologischen Filmtheorie in basalen Grundzügen erläutert, inwiefern ein Film als ein Ereignis aufzufassen ist, von dem der Zuschauer immer schon Teil ist und mit dem er in einem Sinnlichkeitskontinuum ist; inwiefern filmische Kommunikation zuallererst einmal ein Wahrnehmungsgeschehen ist. $^{21}$

16 Morsch: Medienästhetik des Films, S. 268, Herv. i. O.

17 Krämer: Sprache - Stimme - Schrift, S. 345.

18 Helmuth Feilke/Angelika Linke: Oberfläche und Performanz - Zur Einleitung. In: Oberfläche und Performanz. Untersuchungen zur Sprache als dynamische Gestalt. Hrsg. v. Angelika Linke und Helmuth Feilke. Tübingen: Max Niemeyer 2009, S. 3-17, hier S. 7.

19 Ebd. (dies lässt sich auch als die Frage nach dem Stil fassen, wie Feilke und Linke hier deutlich machen).

20 Krämer: Was haben ,Performativität‘ und ,Medialität‘ miteinander zu tun?, S. 21.

21 Zu einer Darstellung und Diskussion des sich vom Textparadigma abgrenzenden filmwissenschaftlichen Diskurses zu Film/Kino als Ereignis vgl. Sabine Nessel: Kino und Ereignis. Das Kinematografische zwischen Text und Körper. Berlin: Vorwerk 2008. 


\subsection{Cinematic communication (Sobchack) - vertigo sehen, hören, spüren}

Im phänomenologischen Modell der „cinematic communication“, wie es Vivian Sobchack im Rahmen ihrer Überlegungen zu Film und Verkörperung entwickelt,, ${ }^{22}$ ist die basale Konstellation ,Film - Zuschauer' als eine Kommunikationssituation aufzufassen. Annahme ist, dass ein Mensch in jenem Moment, wo er der Zuschauer eines Films ist, in einen vitalen Austausch involviert ist - in einen Austausch, der sich zwischen Film und Zuschauer ereignet. Film wird dabei als ein „nonhuman lived body" aufgefasst, als ein nicht-anthropomorpher, aber doch lebendiger Leib, der immer eine spezifische Weise des Zur-Welt-Seins realisiert. ${ }^{23}$ Vom Film ist dabei nicht als etwas Gegebenem die Rede, sondern als etwas grundsätzlich Zeitlich-Dynamischem: Film ist eine Figuration (,that figuration we call a film“), ein Werden (,the film exists for us as always in the act of becoming“). ${ }^{24}$ Und der Modus, in dem sich die Filmfiguration ereignet, ist der eines immer schon doppelten, ineinander verschränkten Wahrnehmungsvollzugs.

Mit einer solchen, sogleich noch weiter erläuterten Auffassung vom Film und seinem Zuschauer setzt sich Sobchack sehr deutlich von alltäglich gängigen Sichtweisen ab. Ein Film wird nicht als ein Kunstwerk oder Produkt, nicht als ein distinktes Objekt oder Artefakt adressiert, das sich der Zuschauer im Kino (oder anderswo) einfach als etwas Gegebenes anschaut; ein Film wird auch nicht im Sinne eines Mediums mit Informationskanälen aufgefasst, das eine Botschaft (bzw. eine Bedeutung) zwischen einem Sender und einem Empfänger transportiert. Mit dem Modell filmischer Kommunikation werden jene Sichtweisen vielmehr überwunden, und psychophysische Modelle von Wahrnehmung, die von einer Subjekt-Objekt-Dichotomie ausgehen, konterkariert. ${ }^{25}$

22 Vgl. vor allem Vivian Sobchack: The Address of the Eye. A Phenomenology of Film Experience. Princeton: Princeton University Press 1992; Vivian Sobchack: What my Fingers Knew. The Cinesthetic Subject, or Vision in the Flesh. In: Carnal Thoughts. Embodiment and Moving Image Culture. Berkeley [u. a.]: Universitiy of California Press 2004, S. 53-84. Vgl. auch Kappelhoff: Kognition und Reflexion, S. 18-25 zur kinematografischen Kommunikation von Dziga Vertov ausgehend.

23 Sobchack: The Address of the Eye, S. 163. Vgl. ausführlich zum Körper des Films ebd., S. 164259.

24 Ebd., S. 54, 60, Herv. i. O.

25 Zentrale Fluchtlinie hierfür sind die Arbeiten von Maurice Merleau-Pontys und dessen Leitgedanke, dass Subjekt und Welt miteinander verflochten sind. Vgl. Maurice Merleau-Ponty: Phänomenologie der Wahrnehmung [1945]. München: De Gruyter 1974; Maurice Merleau-Ponty: Das Kino und die neue Psychologie [1947]. In: Philosophie des Films. Grundlagentexte. Hrsg. v. Dimitri Liebsch. Paderborn: Mentis 2005, S. 70-84; Maurice Merleau-Ponty: The Child's Relation with Others [1951]. In: The Merleau-Ponty Reader. Hrsg. v. Ted Toadvine und Leonard Lawlor. 
Der Moment, in dem ein Film zur Aufführung kommt, ist in einer besonderen Weise ein Wahrnehmungsgeschehen. Denn der Film nimmt an der kommunikativen Situation als eine Instanz teil, die eine Welt wahrnimmt und zugleich immer schon sich selbst eben in diesem Wahrnehmen zeigt. Was ein Film seinem Zuschauer zeigt, ist daher auch viel mehr als einfach nur Repräsentationen von Wirklichkeit auf einer Leinwand. Es würde zu kurz greifen, einfach nur zu sagen, dass man Schauspieler, Objekte oder Räume gezeigt oder Dialoge zu hören bekommt. Denn audiovisuelle Bilder zeigen immer schon auch einen Wahrnehmungsakt: „Watching a film, we can see the seeing as well as the seen, hear the hearing as well as the heard, and feel the movement as well as see the moved.“26 In diesem Sinne ist dem Zuschauer mit dem audiovisuellen Bild ein auf Etwas gerichtetes Wahrnehmen als expressive Aktivität gegenwärtig - er erlebt eine zum Ausdruck gekommene Wahrnehmungserfahrung. Die Beziehung zwischen und der Austausch von Zuschauer und Film bestimmt Sobchack daher über ein Verkörperungsmoment, das sie als „an expression of experience by experience“ fasst. $^{27}$

Das Prinzip dieses Gedankens sei mit Alfred Hitchcocks Film einer in Trugbildern gründenden tragischen Liebe illustriert, auf den auch im weiteren Verlauf immer wieder zurückgekehrt werden wird: mit vERTIGo (USA 1958). Dessen Handlungskonstellation lässt sich wie folgt resümieren: Scottie (James Stuart), der nach einem traumatischen Unfall und tödlichen Sturzes eines Kollegen an Höhenangst leidet und deshalb aus dem Polizeidienst ausgeschieden ist, wird von seinem früheren College-Freund Gavin Elster (Tom Helmore) benutzt, um in seiner höhenangstbedingten Hilflosigkeit den vermeintlichen Selbstmord - ein Sturz von einem Glockenturm herab - von dessen Frau Madeleine zu bezeugen. Scottie wird hierfür mit Judy (Kim Novak) in Kontakt gebracht, die für Scottie Madeleine verkörpert: eine junge Frau, von der eine Tote - ihre Urgroßmutter: die Selbstmörderin Carlotta Valdes - Besitz ergriffen zu haben scheint. Scottie wird Madeleine, in die er sich verliebt, zweimal verlieren: einmal im Zuge des von Gavin inszenierten Falls aus dem Glockenturm (1. Akt); und ein zweites Mal, als er, ein weiteres Mal traumatisiert, Judy trifft, in ihr sich an Madeleine erinnert fühlt, sie wieder zu Madeleine macht, und, als er den Betrug an sich entdeckt, mit ihr zum Glocken-

Evanston: Northwestern University 2007, S. 143-183; Maurice Merleau-Ponty: Das Sichtbare und das Unsichtbare. Gefolgt von Arbeitsnotizen [1964]. 2. Auflage. München: Fink 1994.

26 Sobchack: The Address of the Eye, S. 10.

27 „More than any other medium of human communication, the moving picture makes itself sensuously and sensibly manifest as the expression of experience by experience“. (Ebd., S. 3 Sobchack nimmt hier Rekurs auf Maurice Merleau-Ponty: The Visible and the Invisible [1964]. Evanston: Northwestern University Press 1968, hier S. 155.) 
turm zurückkehrt - Judy verliert den Halt und stürzt in den Tod (2. Akt). Betrachtet sei der Beginn einer Szene aus der Anfangsphase des Films, in der Scottie zum ersten Mal der todessehnsüchtigen Frau seines Freundes begegnet, die er beschatten soll: Madeleine. Mit den Worten „You can see her there“ ist Scottie hierfür in das elegante, voll besetzte ,Ernie’s Restaurant‘ bestellt worden. ${ }^{28}$

Der Zuschauer sieht zunächst Scottie, wie er mit einem beobachtenden Blick an der Bar des Restaurants sitzt - ohne dass man sehen würde, was er beobachtet. Dann jedoch löst sich die Kamera von Scottie und bewegt sich durch das Restaurant, bis schließlich Madeleine gezeigt wird, die mit ihrem Mann an einem der vielen Tische sitzt. So sieht der Zuschauer das Gesehene, also das, was die Kamera hier in den Blick nimmt: einen beobachtenden Mann und eine beobachtete Frau in einem vollen Restaurant. Zugleich ist $\mathrm{zu}$ erleben, wie Scottie/Stewart und Madeleine/Novak gesehen werden - der Zuschauer sieht ein Sehen: Er sieht, wie Madeleine/Novak mit ihrem grünen, ausladenden Abendkleid ins Zentrum der Aufmerksamkeit rückt - inmitten der leuchtend rot ausgekleideten Wände des Restaurants und der in dunklen Schwarz-, Grau- und Silbertönen changierenden Masse seiner Gäste. Und zugleich ist diese Einstellung eine Bewegung, die der Zuschauer spürt: Mit einer einzigen, lang andauernden Aufnahme bewegt sich die Kamera langsam durch den Raum, rückwärts von Scotties beobachtendem Blick sich entfernend und dabei zugleich seiner Blickachse folgend, sodass der $\mathrm{Zu}$ schauer ein horizontales Gleiten über ein Ensemble dicht stehender, voll besetzter Tische und sich zwischen ihnen hindurchbewegende Kellner und Gäste erfährt bis dann ein kurzes Innehalten der Kamera wahrzunehmen ist und ein anschließendes Wiederaufnehmen der Bewegung, nun mit veränderter Richtung, nach vorne, in einer sehr fokussierten Weise: ein sehr sanftes und langsames Annähern an und Angezogen-Sein von einer Frau - Madeleine. Und der Zuschauer hört ein Hören: Er hört, wie die akustische Atmosphäre des Restaurants - ein unbestimmtes Gewirr von Stimmen und klapperndem Geschirr - von einer sanften, melancholischen Streichermusik abgelöst wird, eben in jenem Moment, wo die Kamera beginnt, sich auf Madeleine/Novak zuzubewegen. (Abb. 7) ${ }^{\star 29}$

28 Eine erste Betrachtung dieser Anfangsphase der Restaurantszene mit Blick auf Sobchacks Modell filmischer Kommunikation erfolgte in Christina Schmitt/Sarah Greifenstein: Cinematic Communication and Embodiment. In: Body - Language - Communication. An International Handbook on Multimodality in Human Interaction, Vol. 2. Hrsg. v. Cornelia Müller, Alan Cienki, Ellen Fricke, Silva H. Ladewig, David McNeill und Sedinha Teßendorf. Berlin/New York: De Gruyter Mouton 2014, S. 2061-2070.

29 Diese sowie ausgewählte weitere Abbildungen finden sich auch als Farbabbildung am Ende des Buches. Darauf wird jeweils in den Abbildungsunterschriften hingewiesen sowie durch ein Sternchen beim Abbildungsverweis im Text. 


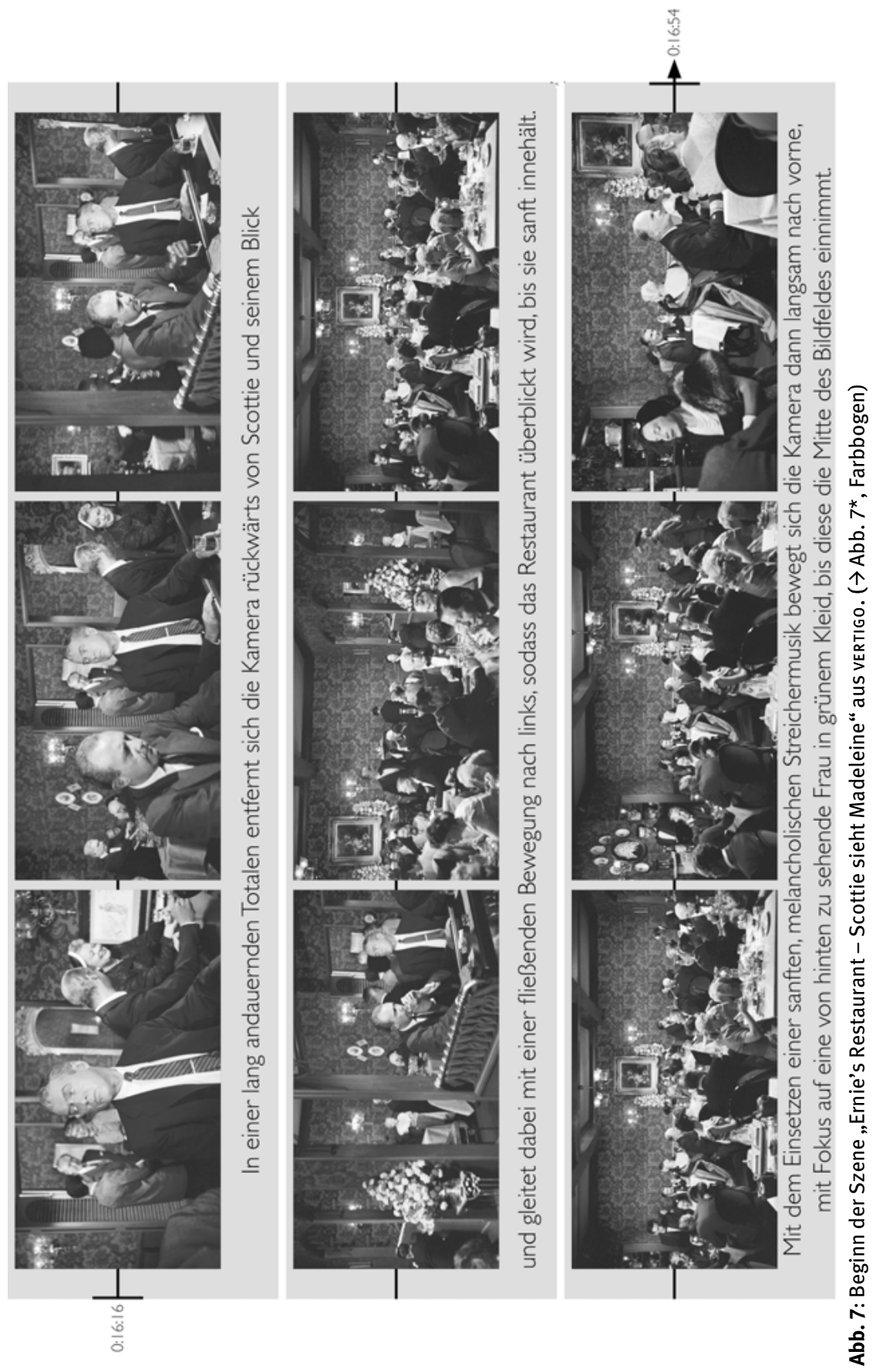


Was ein Zuschauer in seinem Wahrnehmungsprozess im Zuge der cinematic communication erfährt, sind also weder bloß Farben, Formen, Bewegungen, Klänge, noch einfach Repräsentationen von Schauspielern, Objekten, Räumen. Der Zuschauer erlebt vielmehr die Wahrnehmung eines Anderen. Dieser ist weder der Filmemacher noch ein Protagonist eines Films, Sobchack zufolge handelt es sich hierbei ganz grundsätzlich - d. h. dies gilt für jeden Film und jeden seiner Momente - um den gegenwärtigen Wahrnehmungsakt eines nicht-menschlichen „anonymous, yet present ,other““. ${ }^{30}$ Und mit eben jenem Wahrnehmungsakt verschränkt sich in der filmischen Kommunikation der Wahrnehmungsakt des Zuschauers. In einer solchen Perspektive meint ,Film“ immer sowohl eine direkte als auch eine mediatisierte Erfahrung. Und beides ist untrennbar miteinander verschränkt, die Wahrnehmung des Zuschauers ist verflochten mit der mediatisierten Wahrnehmungsform des Films. So ist es bei vertigo der Zuschauer, der Madeleine/Novak erblickt, aber er tut dies, indem er, folgt man Sobchack, die Wahrnehmung eines intentionalen, anonymen Anderen verkörpert.

Mit Rückgriff auf eine Überlegung Gertrud Kochs zum Aspekt der Performativität beim audiovisuellen Bild ${ }^{31}$ lässt sich das Wahrnehmen eines Films durch einen Zuschauer denn auch als ein Handeln begreifen - wenn man dieses Handeln im Sinne einer „Aktivität des Zuschauers“ fasst, die zugleich ein „Bestimmtwerden durch das Anspielen einzelner Sinne“ ist: Die „Überzeugungen“, die der Zuschauer im Zuschauen gewinnt, basieren daher „nicht auf strikten Schlussfolgerungen“, sondern sind „medial vermittelte Bestimmungen“ - d. h. Bestim-

30 Sobchack: The Address of the Eye, S. 9.

31 Morsch hat darauf hingewiesen, dass es keinesfalls als abschließend geklärt betrachtet werden kann, „was Performativität eigentlich meint, noch dazu im Filmmedium“ (Morsch: Wahrgenommene Wahrnehmung, gesehenes Sehen, S. 259). Dies liegt nicht zuletzt daran, dass der Begriff des Performativen vom wissenschaftlichen Diskurs zu audiovisuellen Bildern noch immer relativ wenig ausgeleuchtet ist - obwohl bereits 1986 auf einer Tagung ein ,performative turn' der Filmwissenschaft ausgerufen wurde (vgl. hierzu Robin Curtis: Deixis, Imagination und Perzeption. Bestandteile einer performativen Theorie des Films. In: Deixis und Evidenz. Hrsg. v. Horst Wenzel und Ludwig Jäger. Freiburg i.Br.: Rombach 2008, S. 241-260, hier S. 241f.). Vgl. zu filmwissenschaftlichen Auffassungen des Performativen vor allem die Arbeiten von Koch, Curtis und Morsch. Bei Koch wird insbesondere eine kulturelle Handlungsmächtigkeit des Films herausgestellt (Koch: Latenz und Bewegung im Feld der Kultur; Gertrud Koch: Vorwort. In: SynästhesieEffekte. Zur Intermodalität der ästhetischen Wahrnehmung. Hrsg. v. Robin Curtis, Marc Glöde und Gertrud Koch. München: Fink 2010, S. 7-9); bei Curtis wird Performativität mit Blick auf die Ereignishaftigkeit der Filmvorführung und die Imagination konzipiert (Curtis: Deixis, Imagination und Perzeption); Morsch verortet das Performative (mit Bezug auf die neophänomenologische Filmtheorie) maßgeblich in der Technik (Morsch: Wahrgenommene Wahrnehmung, gesehenes Sehen; Morsch: Medienästhetik des Films). 
mungen, die der Zuschauer trifft und die auch auf ihn treffen. ${ }^{32}$ In phänomenologischer Perspektive hat man es insofern beim Zuschauen mit einem dialektisch konzipierten Wahrnehmungsprozess zu tun, bei dem „Sinnbildung weder vorgeprägtes Sinn-Sein noch spontan gesetztes Sinn-Erfinden“ und „der Wahrnehmungsprozess kein bloß rezeptiver Vorgang, innerhalb dessen ein vorgegebener Sinn lediglich erkannt werden würde“: Das Wahrnehmen und das Wahrgenommene vermengen und vermischen sich in einer Weise, „die auf kein stabiles Innen oder Außen mehr abhebt“. ${ }^{33}$ Denn ,Film‘ meint eine wahrnehmbare, in sich selbst (d. h. im audiovisuellen Bild) und zugleich im Zuschauerkörper verankerte Wahrnehmungsaktivität; eine wahrnehmbare Wahrnehmungsaktivität, die somit zugleich Perzeption und Ausdruck ist, weshalb sich letztlich auch das Sinnliche des Wahrnehmens („having sense“) und das Sinn-Machen („making sense“) miteinander verschränken und eins sind: ${ }^{34},[. .$.$] the film is experienced and under-$ stood for what it is: a visible and centered visual activity coming into being in significant relation to the objects, the world, and the others it intentionally takes up and expresses in embodied vision.“35

In gewisser Weise haben wir es bei der Filmwahrnehmung also tatsächlich in einem ganz grundsätzlichen Sinne mit einem $\mathrm{Zu}$-Schauen zu tun, d. h. mit einem Schauen, das sich zu einem anderen fügt. ${ }^{36}$ Und in diesem $\mathrm{Zu}$-Schauen empfängt und verkörpert der Zuschauer eine konkrete Welt-Erfahrung, eine spezifische Weise des Zur- und In-der-Welt-Seins, die das audiovisuelle Bild hervorbringt. ${ }^{37}$ Indem sein Seh- und Hörsinn angespielt werden, erlebt der Zuschauer in seinem Sehen und Hören gewissermaßen ein Verhalten aus einer Binnenperspektive

32 Ich führe hier einen (wiederum im Rückgriff auf Seel entstehenden) Gedanken Gertrud Kochs zum Aspekt der Performativität beim audiovisuellen Bild weiter. Vgl. Koch: Vorwort, S. 9, sowie Seel: Ein revidierter Begriff der Selbstbestimmung, S. 293.

33 So Reicherts Resümee des mit Merleau-Pontys Begriff des Chiasmus' gegebenen Wahrnehmungsverständnisses (Ramón Reichert: Die Entregelung der Sinne. Eine Theorieperspektive zur Filmphänomenologie. In: montage AV19.1 (2010), S. 101-115, hier S. 110f.).

34 Sobchack: The Address of the Eye, S. 13.

35 Ebd., S. 171.

36 Hierin zeigt sich denn auch die Besonderheit filmischer Kommunikation im Vergleich mit der zwischenmenschlichen. Vgl. Merleau-Ponty: The Child's Relation with Others sowie auch Schmitt/Greifenstein: Cinematic Communication and Embodiment.

37 Dieses Spezifische ist hierbei zum einen grundsätzlich mit Blick auf das Filmische zu verstehen, insofern die Weise der filmischen Wahrnehmung sich von der menschlichen unterscheidet. Und es ist zum anderen hinsichtlich eines jeden Films als Ganzem im Verhältnis zu anderen Filmen zu sehen, nicht zuletzt auch in Bezug auf das dynamische Wahrnehmungsgeschehen innerhalb eines Films. 
heraus - einer Perspektive, die nicht die seine ist und sich doch in ihm verankert, ${ }^{38}$ aufgrund einer für den Film grundlegenden direkten Reflexivität:

\begin{abstract}
Writing of human vision and our understanding that others also see as we do, MerleauPonty tells us: ,As soon as we see others ... henceforth, through other eyes we are for ourselves fully visible ... For the first time, the seeing that I am is for me really visible; for the first time I appear to myself completely turned inside out under my own eyes. 'Prior to the cinema this visual reflexivity in which we see ourselves seeing through other eyes was accomplished only indirectly: that is, we understood the visions of others as structured similarly to our own only through looking at - not through - the intentional light in their eyes and the investments of the objective behavior. The cinema, however, uniquely materialized this visual reflexivity and philosophical turning directly - that is in an objectively visible but subjectively structured vision we not only looked at but also looked through. ${ }^{39}$
\end{abstract}

Verkörperte Wahrnehmung wird damit bestimmt als „the intersubjective basis of objective cinematic communication“. ${ }^{40}$ Und zugleich weist dies auf Folgendes hin: Ein Film zeigt nicht nur das (Wahrnehmungs-)Verhalten von Figuren/ Schauspielern - etwa die Art und Weise, wie in der oben skizzierten vertigoSzene Scottie/Stuart mit gespanntem Körper unbeweglich zur Seite blickt. Vielmehr lässt sich ebenso, wie Thomas Morsch festhält, „ein beobachtbares Verhalten des Films “41 beschreiben - im Sinne einer Wahrnehmung, die zum Ausdruck kommt; einer Wahrnehmungserfahrung, die ein je spezifisches „being-inthe world" entwirft; einer Wahrnehmung, die der Zuschauer sinnlich-reflexiv erfährt. Dem lässt sich mit Ausführungen zu Bewegung und filmischer Expressivität konkretisierend nachgehen.

\title{
8.3 Eine gestische Dimension: Bewegungsfigurationen als ,Verhalten des Films“
}

Die Auffassung, dass audiovisuelle Bilder über eine zum Ausdruck kommende Wahrnehmung kommunizieren, die im Zuschauerkörper ihren Resonanzraum findet, ist nun fortzuführen - anhand des Gedankens, dass sich dem Zuschauer ein „Verhalten des Films“ als filmische Bewegungsfiguration zeigt. Es sei darauf hingewiesen, dass von, Verhalten ' hier entsprechend nicht im Sinne eines Readymades, eines bloß noch instanziierten, weil (genetisch) vorprogrammierten Ver-

38 Vgl. Sobchack: The Address of the Eye, S. 128-143.

39 Sobchack: The Scene of the Screen, S. 149, Herv. i. O. Das Binnenzitat stammt aus MerleauPonty: The Visible and the Invisible, S. $143 \mathrm{f}$.

40 Sobchack: The Address of the Eye, S. 5.

41 Morsch: Medienästhetik des Films, S. 166. 
haltensmusters die Rede ist. Vielmehr ist im Folgenden ,Verhalten“ dezidiert phänomenologisch adressiert und von der Bewegung aus gedacht. Erst unter diesen eng miteinander verwobenen Voraussetzungen kann in den Blick kommen, was für die hier verfolgte Idee des Metaphorisierens zentral ist: „the consequential dynamic relationship of perception to movement, the significance of freely varied movement, [...] the integral role of emotion in perception and cognition“42 (um mit den Worten der Philosophin Maxine Sheets-Johnstone zu sprechen, auf die im weiteren Verlauf noch zurückzukommen sein wird). Erst dann ermöglicht das Sondieren einer gestischen Dimension, wie es Anliegen des aktuellen Kapitels ist, Film und Zuschauer nicht als fixe, voneinander getrennte Gegebenheiten zu begreifen, sondern als immer im Werden begriffene, miteinander verschränkte Phänomene von Zeitgestalten. ${ }^{43}$

Eine Fokusverlagerung ermöglicht es, sich der Idee einer Bewegungsfiguration und damit einem Verhalten des Films in einem ersten Schritt zu nähern: Es sei für einen Moment das gegenständlich-darstellende Vermögen audiovisueller Bilder (bzw. unser gegenständliches Wahrnehmungsvermögen), ${ }^{44}$ das die Betrachtungsweise so schnell $\mathrm{zu}$ vereinnahmen vermag, ganz in den Hintergrund gerückt. Es tritt alsdann eine instruierende Analogie zwischen Musik und audiovisuellem Bild in den Vordergrund - eine Analogie, die in der ästhetischen Dimension zu finden ist.

Musik, die wir hören, ist zunächst einmal Klang, ohne dass unsere gegenständliche Wahrnehmung angesprochen wird. Gehörte Musik - das sind Töne, die sich in der Zeit entfalten, die nicht als singuläre Entitäten, sondern als eine Melodie hörbar sind; das sind wahrgenommene Bewegungsfigurationen, die sich über Rhythmus, Tempo, Klangfarbe usw. ausbilden. Denn zur ästhetischen Erfahrung gehört

42 Maxine Sheets-Johnstone: Getting to the Heart of Emotions and Consciousness. In: Handbook of Cognitive Science. An Embodied Approach. Hrsg. v. Paco Calvo und Antoni Gomila. Amsterdam [u. a.]: Elsevier 2008, S. 453-465, hier S. 455, 457.

43 Kappelhoff beschreibt, in Rückgriff auf John Dewey, dieses Werden in der ästhetischen Erfahrung als ein Subjektivierungsprozess, der in einem reflexiven Gefühl gründet (vgl. Hermann Kappelhoff: Genre und Gemeinsinn. Hollywood zwischen Krieg und Demokratie. Berlin/Boston: Walter de Gruyter 2016, hier S. 116, 119).

44 Gegenständliches Wahrnehmen beschreibt der Psychologe und Phänomenologe Fuchs als aktive Wahrnehmungsdimension, die als ihren Gegenpol die Ausdruckserfassung hat, beschrieben als partizipierende Wahrnehmungsdimension (Thomas Fuchs: Psychopathologie von Leib und Raum. Phänomenologisch-empirische Untersuchungen zu depressiven und paranoiden Erkrankungen. Darmstadt: Steinkopf 2000, hier S. 36-40; vgl. auch Fußnote 68 im vorliegenden Kapitel 8). 
ein sinnlich körperhaftes, ,vorprädikatives‘ Auffassen und Verstehen [...], im Fall der Musik ein gleichsam mimetisches Nachvollziehen von Klanggesten und Klangverläufen, das Auffassen einer Signifikanz, die wir (noch) nicht in Worte fassen können, obwohl sie immer auch eine Provokation unseres produktiven Sprachvermögens darstellt. ${ }^{45}$

Und auch audiovisuelle Bilder lassen sich über die Inszenierung auf einer Ebene ästhetischer, dynamischer Bewegungsmuster greifen, denen eine spezifische Temporalität eignet. Was mit solchen Bewegungsfigurationen angesprochen ist, ist die filmische Expressivität: Es geht um eine Expressivität, die sich durch das Zusammenspiel audiovisueller Inszenierungsebenen - etwa Kameraführung, Bildkomposition, Sound, Montage usw. - gestaltet und ausformt; es geht um eine Expressivität, die die Wahrnehmung und das Empfinden von Zuschauern modelliert. Kurz: Mit solchen Bewegungsfigurationen geht es um die filmische Ausdrucksbewegung. Von Relevanz ist damit ein in der Traditionslinie ästhetischphilosophischer Filmtheorie stehendes Modell zur Emotionsgestaltung, ${ }^{46}$ wie es

45 Albrecht Wellmer: Das musikalische Kunstwerk. In: Falsche Gegensätze. Zeitgenössische Positionen zur philosophischen Ästhetik. Hrsg. v. Andrea Kern und Ruth Sonderegger. Frankfurt a. M.: Suhrkamp 2002, S. 133-175, hier S. 167, zitiert nach Morsch: Medienästhetik des Films, S. $273 \mathrm{f}$. Johnson adressiert eine solche ästhetische Dimension von Bedeutung ganz ähnlich für den Bereich der Bildenden Künste: „In the visual arts, it is images, patterns, qualities, colors, and perceptual rhythms that are the principal bearers of meaning. The obvious fact that we usually cannot put into words, what we have experienced in our encounter with an artwork does not make the embodied, perceptual meaning any less a type of meaning." (Johnson: The Meaning of the Body, S. 234)

46 Tröhler und Hediger sehen die filmwissenschaftliche Debatte zu ,Film und Emotion“ im Wesentlichen durch eine ästhetisch-philosophisch und eine kognitionswissenschaftlich-psychologisch orientierte Argumentationslinie geprägt (Margit Tröhler/Vinzenz Hediger: Ohne Gefühl ist das Auge der Vernunft blind. Eine Einleitung. In: Kinogefühle. Emotionaliät und Film. Hrsg. v. Matthias Brütsch, Vinzenz Hediger, Ursula von Keitz und Margit Tröhler. Marburg: Schüren 2005, S. 7-20). Ästhetisch-philosophisch ausgerichtete filmtheoretische Positionen verorten „die Empfindungen, Emotionen, Affekte oder Gefühle im Filmerleben tendenziell auf der Ebene körperlicher, wahrnehmungsbedingter und auch unbewusster Vorgänge“, wohingegen kognitionswissenschaftlich-psychologisch ausgerichtete filmtheoretische Positionen davon ausgehen, „dass sich bei den Zuschauern erst auf der Basis des bewussten und kognitiven Verstehens Emotionen ausbilden“ (Greifenstein: Tempi der Bewegung - Modi des Gefühls (Manuskriptfassung), S. 19f.). Für grundlegende Übersichten zum Forschungsfeld ,Film und Emotion` vgl. Tröhler/Hediger: Ohne Gefühl ist das Auge der Vernunft blind; Anne Bartsch/Jens Eder/Kathrin Fahlenbrach: Einleitung: Emotionsdarstellung und Emotionsvermittlung durch audiovisuelle Medien. In: $A u$ diovisuelle Emotionen. Emotionsdarstellung und Emotionsvermittlung durch audiovisuelle Medienangebote. Hrsg. v. Anne Bartsch, Jens Eder und Kathrin Fahlenbrach. Köln: Halem 2007, S. 8-38; Hermann Kappelhoff/Jan-Hendrik Bakels: Audiovisuelle Affekte - die Emotionstheorie des Films im Spannungsfeld von früher Filmtheorie, Kognitionstheorie und Medienästhetik. In: Emotionen. Ein interdisziplinäres Handbuch. Hrsg. v. Hermann Kappelhoff, Jan-Hendrik Bakels, Hauke Lehmann und Christina Schmitt, Stuttgart: J.B. Metzler 2019, S. 445-451. 
Hermann Kappelhoff maßgeblich in seiner kulturgeschichtlichen Studie zum Filmmelodram entfaltet hat. ${ }^{47}$ Denn mit der filmischen Ausdrucksbewegung lässt sich ein ästhetisch orchestriertes „Zuschauergefühl“ in den Blick nehmen. ${ }^{48}$

Die filmische Ausdrucksbewegung ist ein Konzept der ästhetischen Emotionsgestaltung audiovisueller Bilder, dessen Theoriegeschichte in der Spätaufklärung ansetzt, genauer: beim Theater der Empfindsamkeit. In Abgrenzung zum Barocktheater und dessen auf Konventionen beruhendem zeichenhaftem Schauspiel entwickelt das theatrale Spiel der Spätaufklärung, wie es die Schauspieltheorien Gotthold Ephraim Lessings und Denis Diderots reflektieren, die Idee des „empfindsamen Gestus“. ${ }^{49}$ Der Grundgedanke dessen ist eine Relation: eine Relation, die sich „in der Beziehung des Zuschauers zur Illusion eines empfindungsvollen lebendigen Körpers zeigt. Sie verwirklicht sich ausschließlich als Relation von Publikum und der illusionären Visualität der Bühne“.50 Den Kern

47 Kappelhoff: Matrix der Gefühle; für eine konzentrierte Darlegung des Konzepts vgl. auch Kappelhoff: Ausdrucksbewegung und Zuschauerempfinden; Thomas Scherer/Sarah Greifenstein/Hermann Kappelhoff: Expressive Movements in Audiovisual Media. Modulating Affective Experience In: Body - Language - Communication. An International Handbook on Multimodality in Human Interaction, Vol. 2. Hrsg. v. Cornelia Müller, Alan Cienki, Ellen Fricke, Silva H. Ladewig, David McNeill und Jana Bressem. Berlin/New York: De Gruyter Mouton 2014, S. 2081-2092.

48 Hermann Kappelhoff/Jan-Hendrik Bakels: Das Zuschauergefühl. Möglichkeiten qualitativer Medienanalyse. In: Zeitschrift für Medienwissenschaft 5.2 (2011), S. 78-95; vgl. auch Kappelhoff: Matrix der Gefühle, S. 87f.; Kappelhoff: Genre und Gemeinsinn, S. 121-123. Vgl. für eine weiterführende Situierung von filmischer Ausdrucksbewegung und Zuschauergefühl im Kontext der filmwissenschaftlichen Debatte zu ,Film und Emotion“ vor allem Kappelhoff/Bakels: Das Zuschauergefühl; Kappelhoff: Genre und Gemeinsinn; Hauke Lehmann: Affektpoetiken des New Hollywood. Suspense, Paranoia und Melancholie. Berlin/Boston: Walter de Gruyter 2017; Jan-Hendrik Bakels: Audiovisuelle Rhythmen. Filmmusik, Bewegungskomposition und die dynamische Affizierung des Zuschauers. Berlin/Boston: Walter de Gruyter 2017; Matthias Grotkopp: Filmische Poetiken der Schuld. Die audiovisuelle Anklage der Sinne als Modalität des Gemeinschaftsempfindens. Berlin/ Boston: Walter de Gruyter 2017; Sarah Greifenstein: Tempi der Bewegung - Modi des Gefühls. Expressivität, heitere Affekte und die Screwball Comedy. Berlin/Boston: Walter de Gruyter 2020. Für eine begriffliche Differenzierung zwischen Emotion, Affekt und Gefühl vgl. Kappelhoff: Genre und Gemeinsinn, S. 116-118.

49 Neben Diderot (Denis Diderot: Das Paradox über den Schauspieler [1778]. In: Ästhetische Schriften, Vol. 2. Hrsg. v. Friedrich Bassenge. Berlin: Das Europäische Buch 1984, S. 481-539) und Lessing (Gotthold Ephraim Lessing: Hamburgische Dramaturgie [1769]. Hrsg. v. Paul Rilla. Berlin: Aufbau 1954) ist auch Engel zentral (Johann Jakob Engel: Ideen zu einer Mimik [1786]. Wuppenau: E\&A Verleger 1994). Vgl. hierzu Kappelhoff: Matrix der Gefühle; Sarah Greifenstein/Hermann Kappelhoff: The Discovery of the Acting Body. In: Body - Language - Communication. An International Handbook on Multimodality in Human Interaction, Vol. 2. Hrsg. v. Cornelia Müller, Alan Cienki, Ellen Fricke, Silva H. Ladewig, David McNeill und Jana Bressem. Berlin/New York: De Gruyter Mouton 2014, S. 2070-2080.

50 Kappelhoff: Matrix der Gefühle, S. 82. 
dieser Relation bildet ein Schauspiel, das in der Zuschauerwahrnehmung rhythmische Figuren als Bilder der Zeit hervorbringt. Und es sind diese zeitlichen Figurationen, die ein „Sichtbarwerden des Affekts als transitorisches Bild“51 evozieren - als „transitorische Malerei“, wie es bei Lessing heißt. ${ }^{52}$

Inwiefern mit der filmischen Ausdrucksbewegung eine ebensolche Relation adressiert ist, ist nun genauer darzulegen. Hierfür sei sich der filmischen Ausdrucksbewegung zunächst über eine ausdruckstheoretische Auseinandersetzung mit dem Phänomen der Amodalität genähert. Denn mit dem Sehen und Hören werden vom audiovisuellen Bild zwar ganz dezidiert einzelne Sinne angespielt, wie Koch es formuliert hat - das Erleben dieses Bildes in der Filmwahrnehmung erschließt sich jedoch nicht erschöpfend, wenn man von getrennten Sinnen ausgeht. ${ }^{53}$ Grundsätzlich ist die Auffassung, die Filmwahrnehmung sei eine synästhetische Überschreitung des Seh- und des Hörsinns, zentral für phänomenologisch orientierte Arbeiten. Vor allem das Haptische der Filmwahrnehmung wird dabei auch immer wieder betont. ${ }^{54}$ Es wird dies auch der Ort einer kurzen Reflexion sein, inwieweit - auch wenn das theoretische Interesse an Amodalität eine Schnittstelle von beiden ist - die Konzepte ,Ausdrucksbewegung and ,Image-Schema‘ nicht ineinander aufgehen, sondern vielmehr auf ganz unterschiedlichen Ebenen liegen. Vor diesem Hintergrund wird das audiovisuelle Bild dann als eine ästhetische Organisation von Wahrnehmung $\mathrm{zu}$ fassen sein. Leitgedanke ist, dass die Idee eines Verhaltens des Films sich in der filmischen Expressivität aufsuchen lässt, in einer gestischen Dimension audiovisueller Bilder gewissermaßen - und damit in einer Dimension, die ein affektives Erleben adressiert; ein Erleben, das sich in der Verschränkung von Film- und Zuschauerwahrnehmung realisiert. Um es mit einer Formulierung Adrian Martins zu sagen: „we join [...] with the flux of the non-representational: the colours, shapes and edits, those gestures of the film itself as a living, breathing, pulsating organ-

51 Ebd., S. 87.

52 Lessing: Hamburgische Dramaturgie, S. 34.

53 Auch Kochs Position steht dem selbstredend nicht entgegen - die oben zitierte Äußerung ist ihrer Einleitung zum Band Synästhesie-Effekte. Zur Intermodalität der ästhetischen Wahrnehmung entnommen.

54 Vgl. vor allem Laura U. Marks: The Skin of the Film. Intercultural Cinema, Embodiment, and the Senses. Durham: Duke University Press 2000; Laura U. Marks: Touch. Sensuous Theory and Multisensory Media. Minneapolis [u. a.]: University of Minnesota Press 2002; Sobchack: What my Fingers Knew; Jennifer M. Barker: The Tactile Eye. Touch and the Cinematic Experience. Berkeley/ Los Angeles/London: University of California Press 2009; aber auch Saige Walton: Cinema's Baroque Flesh. Film, Phenomenology and the Art of Entanglement. Amsterdam: Amsterdam University Press 2016. 
ism“". ${ }^{55}$ Illustrierend wird für diese gestische Dimension audiovisueller Bilder ${ }^{56}$ auf die zuvor betrachtete vERTIGo-Szene zurückgekommen, um die Idee einer zum Ausdruck kommenden verkörperten Wahrnehmung im Rahmen des Konzepts der filmischen Ausdrucksbewegung auch filmanalytisch weiter zu präzisieren. Dies bildet den Hintergrund einer kurzen Reflexion zu Ähnlichkeiten filmischer und menschlicher Expressivität. Abschließend wird die grundsätzliche Auffassung einer Genese von Bedeutung erläutert, wie sie dem Konzept filmischer Expressivität inhärent ist.

\section{Ausdruckstheorie - Amodalität (Stern, Plessner) ${ }^{57}$}

Schon bei Aristoteles findet sich der Gedanke, dass es der menschlichen Wahrnehmung zu eigen ist, „Empfindungsqualitäten wahrzunehmen, die, weil sie nicht exklusiv an einen einzigen Sinn gebunden sind wie zum Beispiel die Farbe an den Gesichtssinn, primären (also amodalen) Charakter haben und allen Sinnen gemeinsam sind“ - so resümiert es Daniel Stern, der sich als Entwicklungspsychologe seit den 1970er Jahren über dynamische Formen des Erlebens mit Phänomenen der Intersubjektivität, der Affektabstimmung auseinandersetzt. ${ }^{58}$ Das Besondere an diesen Empfindungsqualitäten ist Stern zufolge, dass sich mit ihnen in der amodalen Wahrnehmung somit weniger „Bilder, Töne, haptische Eindrücke und benennbare Objekte, sondern vielmehr [...] Formen, Intensitätsgrade und Zeitmuster - die eher ,globalen' Merkmale des Erlebens“ realisieren. ${ }^{59}$ Und die menschliche Wahrnehmung bestimmt sich wesentlich über den Aspekt des Amodalen. Denn diese globalen Merkmale des Erlebens - Formen, Intensitä-

55 Adrian Martin: Delirious Enchantment. In: Senses of Cinema 5 (2000), zitiert nach Morsch: Medienästhetik des Films, S. 307.

56 Vgl. zu Geste und Film auch Koch: Die Wiederkehr der Illusion, S. 247-275; Greifenstein: Tempi der Bewegung - Modi des Gefühls.

57 Die Ausführungen zum Begriff der Amodalität in der Ausdruckstheorie bauen auf auf Vorarbeiten in Christina Schmitt: Embodied Meaning in Audio-Visuals. First Steps Towards a Notion of Mode. In: Building Bridges for Multimodal Research. International Perspectives on Theories and Practices of Multimodal Analysis. Hrsg. v. Janina Wildfeuer. Bern/New York: Peter Lang 2015, S. 309-325.

58 Daniel N. Stern: Die Lebenserfahrung des Säuglings [1985]. Stuttgart: Klett-Cotta 1992, hier S. 220. Amodalität ist bei Aristoteles im Kontext seines komplexen Konzepts des „sensus communis“ zu verorten (vgl. Pavel Gregoric: Aristotle on the Common Sense. Oxford: Oxford University Press 2007).

59 Stern: Die Lebenserfahrung des Säuglings, S. 80. 
ten und Zeitmuster - sind beheimatet in den „kinetischen Gestalten“ („Konfigurationen, die sich in der Zeit verändern“), aus denen das menschliche Verhalten wesentlich besteht. ${ }^{60}$ Eine kinetische Gestalt, die sich im Verhalten zeigt und es gestaltet, weist mehrere Aspekte vor, die Stern als konstitutiv miteinander verbunden erachtet, also nur theoretisch separiert: „Bewegung, Zeit, Kraft, Raum und Intention/Gerichtetheit“61 verschmelzen im Wahrnehmungserleben $\mathrm{zu}$ „Ganzheiten oder Gestalten und emergenten Eigenschaften“. ${ }^{62}$

Von einem solchen Amodalitäts-Verständnis, das so stark auf Bewegung abzielt und dies im Kontext mit Verhalten denkt, ziehen sich signifikante Verbindungslinien zu den Wahrnehmungs- und Ausdruckstheorien vom späten neunzehnten Jahrhundert bis zur Mitte des zwanzigsten Jahrhunderts. Beispielsweise resoniert darin Merleau-Pontys phänomenologische Sicht auf die Synästhesie: ${ }^{63}$

Die Rede vom Sehen von Tönen oder vom Hören von Farben hat ihren Sinn, insofern Gesicht und Gehör nicht bloße Verfügung über ein undurchsichtiges quale, sondern Beispiele von Modalitäten der Existenz, Synchronisierungen des Leibes mit diesen sind; und das Problem der Synästhesien beginnt sich zu lösen, wenn wir begreifen, daß jede Erfahrung einer

60 Ebd., S. 220.

61 Daniel N. Stern: Ausdrucksformen der Vitalität. Die Erforschung dynamischen Erlebens in Psychotherapie, Entwicklungspsychologie und den Künsten [2010]. Frankfurt a. M.: Brandes \& Apsel 2011, hier S. 13.

62 Ebd., S. 14. Bei Fahlenbrach findet das Konzept der Amodalität nicht zuletzt bei ihren an Chions Synchrese-Konzept anschließenden Ausführungen zu perzeptiven Grundstrukturen von Bild-Ton-Verbindungen Beachtung. Vgl. Fahlenbrach: Audiovisuelle Metaphern, S. 136-142, hier insbesondere 139f.; zur Synchrese vgl. Michel Chion: Audio-Vision. Sound on Screen [1991]. New York: Columbia University Press 1994. Verwiesen wird bei Fahlenbrach allerdings vor allem auf neurologisch orientierte wahrnehmungspsychologische Forschungen zur intermodalen Assoziation, wo „Intensität, Dauer/Rhythmus, Lage (damit verbunden auch: Position/Richtung)“ als „Reizmerkmale[], gefasst werden, die „in sämtlichen Sinnessystemen erfasst werden“ (Fahlenbrach: Audiovisuelle Metaphern, S. 53-55, hier S. 54, Herv. i. O.). Eine ausdruckstheoretische Situierung von amodaler Wahrnehmung, wie dies bei Stern erfolgt - und wie es auch für die vorliegende Arbeit tut -, wird bei Fahlenbrach nicht vorgenommen.

63 Vgl. Merleau-Ponty: Phänomenologie der Wahrnehmung, S. 264-275, hier insbesondere S. 268. Vgl. zu aktuellen Diskussionen des Synästhesie-/Amodalitäts-Phänomens im Kontext ästhetischer Wahrnehmung Robin Curtis/Marc Glöde/Gertrud Koch (Hrsg.): Synästhesie-Effekte. Zur Intermodalität der ästhetischen Wahrnehmung. München: Fink 2010; Sabine Flach/Jan Soeffner/ Joerg Fingerhut (Hrsg.): Habitus in Habitat III - Synaesthesia and Kinaesthetics. Bern [u. a.]: Peter Lang 2011; Robin Curtis/Gertrud Koch/Marc Siegel: Synchronisierung der Künste. München: Wilhelm Fink 2013. Vgl. zur Synästhesie als Diskursphänomen Melanie Gruß: Synästhesie als Diskurs. Eine Sehnsuchts- und Denkfigur zwischen Kunst, Medien und Wissenschaft. Bielefeld: transcript 2017. 
Qualität in Wahrheit Erfahrung einer bestimmten Weise der Bewegung und des Verhaltens sind. ${ }^{64}$

So, wie Stern in den amodalen kinetischen Gestalten etwas für das menschliche Verhalten ganz Alltägliches sieht, versteht auch Merleau-Ponty, für den sich im Verhalten immer Weisen eines Zur-Welt-Seins zeigen, die synästhetische Wahrnehmung als die Regelwahrnehmung und nicht als wahrnehmungspsychologischen Sonderfall einiger weniger Synästhetiker. ${ }^{65}$ Wenn Stern sich wiederum der „,Dynamik‘ der [...] Vorgänge [...], aus denen die interpersonalen psychologischen Momente unseres Lebens bestehen“, zuwendet, zeigt sich, dass der Gedanke der Amodalität grundsätzlich an einem Kern der Ausdruckstheorie rührt. Denn Stern illustriert seine These des alltäglichen Erlebens kinetischer Gestalten nicht zuletzt an gestischen und mimischen Bewegungen - an Bewegungen also, die der Ausdruckstheorie (wie sie sich in psychologischen, linguistischen, ästhetisch-philosophischen und kunstheoretischen sowie in philosophisch-anthropologischen Schriften artikuliert) ${ }^{66}$ als paradigmatisch für ihr Konzept der Ausdrucksbewe-

64 Merleau-Ponty: Phänomenologie der Wahrnehmung, S. 273f., Herv. i. O. Vgl. darüber hinaus ebd., S. 264-275, hier insbesondere S. 268. Auch Merleau-Ponty streift hier das „sensorium commune“, allerdings primär in Bezug auf Herders Abhandlung zum Ursprung der Sprache Johann Gottfried Herder: Abhandlung über den Ursprung der Sprache [1772]. In: Johann Gottfried Herder. Sprachphilosophie. Ausgewählte Schriften. Hrsg. v. Erich Heintel. Hamburg: Felix Meiner 2005, S. 1-87) und nicht, wie Stern, in Bezug auf Aristoteles. Vgl. zu Herder, auch im Vergleich zu Aristoteles: Sugiyama Takashi: Herder's Theory of Common Sense. The Birth of the Concept of Synesthesia. In: Aesthetics (The Japanese Society for Aesthetics) 13 (2009), S. 69-81. In editorischer Hinsicht sei angemerkt, dass Herder für Merleau-Ponty hier vermutlich keine Primärquelle ist, sondern er im Rahmen seiner Lektüre des Entwicklungspsychologen Heinz Werner auf Herder stößt, und in diesem Zuge stellt sich ein Zitationsfehler ein: Heißt es bei Herder noch „Wir sind ein denkendes sensorium commune“ (Herder: Abhandlung über den Ursprung der Sprache, S. 38), wird aus dem denkenden sensorium commune im Zitat bei Merleau-Ponty ein „dauerndes“ (i. O.: „perpétuel“).

65 Vgl. für eine Übersicht hierzu Hinderk M. Emrich: Wahrnehmung und Empfindung in synästhetischen Welten. In: Synästhesie-Effekte. Zur Intermodalität der ästhetischen Wahrnehmung. Hrsg. v. Robin Curtis, Marc Glöde und Gertrud Koch. München: Fink 2010, S. 11-25.

66 Wilhelm Wundt: Grundzüge der physiologischen Psychologie. 2. Auflage. Leipzig: Wilhelm Engelmann 1880; Wilhelm Wundt: Grundriss der Psychologie. Leipzig: Wilhelm Engelmann 1896; Bühler: Ausdruckstheorie; Konrad Fiedler: Moderner Naturalismus und künstlerische Wahrheit [1881]. In: Schriften zur Kunst I. München: Wilhelm Fink 1991, S. 82-110; Konrad Fiedler: Über den Ursprung der künstlerischen Tätigkeit [1887]. In: Schriften zur Kunst I. München: Wilhelm Fink 1991, S. 112-220; Georg Simmel: Aesthetik des Porträts [1905]. In: Aufsätze und Abhandlungen 1901-1908, Vol. 1. Frankfurt a. M.: Suhrkamp 1995, S. 321-332; Georg Simmel: Die ästhetische Bedeutung des Gesichts [1901]. In: Aufsätze und Abhandlungen 1901-1908, Vol. 1. Frankfurt a. M.: Suhrkamp 1995, S. 36-42. 
gung gelten. So hebt Stern exemplarisch „die Kraft, das Tempo und den Fluss einer Geste [...] [,] die Art, wie sich ein Lächeln auf einem Gesicht ausbreitet, oder den zeitlichen Verlauf seines Erstarrens" hervor. ${ }^{67}$ An gestischen und mimischen Bewegungen (und letztlich auch in Fortführung der Auseinandersetzungen mit dem Schauspiel in der Spätaufklärung) hat die moderne Ausdruckstheorie einen ihrer zentralen Grundgedanken entwickelt, der in Sterns Rede von den kinetischen Gestalten als den interpersonalen psychologischen Momenten seine Weiterführung findet: In einer Ausdrucksbewegung ereignet sich eine intersubjektive Affektabstimmung (man kann hier auch von Interaffektivität sprechen), es handelt sich um ein Ausdrucksgeschehen, das auch ein Wahrnehmungsgeschehen ist. $^{68}$ In diesem modernen, gewissermaßen performativen Verständnis von Ausdruck ist dieser denn auch gerade keine „Oberfläche“ mehr, „hinter oder unter der sich das Wesentliche, nämlich die Innensphäre verbirgt" ${ }^{\text {69 }}$ - ist es doch der Ausdruck selbst, der wesentlich ist.

Im Blick zu behalten ist, dass mit ,Ausdrucksbewegung' hier nicht von einem bestimmten Typ von Bewegung die Rede sein soll, wie dies beispielsweise der Philosoph und Kognitionswissenschaftler Shaun Gallagher in jüngerer Zeit vorgeschlagen hat. Jener sieht im „expressive movement“ einen Bewegungstyp neben anderen: Gestikulieren und Zeigen werden als Ausdrucksbewegungen erachtet, Greifen indes gilt ihm als instrumentelle Bewegung, Gehen wiederum als Fortbewegung. ${ }^{70}$ In Rückbezug auf den Anthropologen Helmuth Plessner hingegen ist mit dem Begriff der Ausdrucksbewegung weniger ein Typ von Bewegung adressiert - vielmehr lässt sich damit eine spezifische Dimension von Bewegung denken. ${ }^{71}$ Dementsprechend erscheinen teils die gleichen Bewegungsbeispiele,

67 Stern: Ausdrucksformen der Vitalität, S. 15.

68 Das „pathisch-rezeptive Moment der Wahrnehmung“, von dem bei Fuchs die Rede ist, welcher einer phänomenologischen Anthropologie verpflichtet ist, ist hier also von Relevanz: „[...] das pathisch-rezeptive Moment der Wahrnehmung [zeigt sich] als sympathetisches Weltverhältnis, das die gesamte Leiblichkeit spürend und mimetisch engagiert. Der Leib berührt, hört und sieht die Dinge, indem er sie, verwandt mit ihnen, in sich widerklingen lässt und so an ihnen partizipiert. Das pathische Moment erfasst als gemeinsame Grundschicht der Sinne ihre intermodalen Qualitäten (Synästhesien, Gestaltverläufe, Intensitätskonturen, Rhythmus, Ausdruck) und damit eine Ähnlichkeit des Stils, der quer zur dinglichen Einteilung der Realität liegt.“ (Fuchs: Psychopathologie von Leib und Raum, S. 39.)

69 Jens Loenhoff: Ausdruck und Vergegenständlichung. In: Kinästhetik und Kommunikation. Ränder und Interferenzen des Ausdrucks. Hrsg. v. Tobias R. Klein und Erik Porath. Berlin: Kulturverlag Kadmos 2013, S. 165-182, hier S. 167.

70 Vgl. Shaun Gallagher: How the Body Shapes the Mind. Oxford: Oxford University Press 2005, hier S. 107-129, hier insbesondere S. 122.

71 Dieser Hinweis findet sich auch in Kappelhoff/Bakels: Das Zuschauergefühl, S. $84 \mathrm{f}$. 
wie sie auch von Gallagher herangezogen werden, bei Plessner in einem anderen Licht, wenn es bei ihm heißt: „Greifen, Fliehen, Abwehren, Suchen, aber auch schon die ,affektlosen“ Formen wie Gehen, Fliegen, Schwimmen [...] stellen [...] Bewegungsbilder dar.“72 Denn was das Konzept der Ausdrucksbewegung adressiert, ist das Wahrnehmen und Empfinden einer spezifischen (und jeweils spezifisch artikulierten) Zeitgestalt:

Wo immer im Reich des Organischen Bewegungen erscheinen, verlaufen sie nach einheitlichem Rhythmus, zeigen sie eine, wohl auch experimentell nachweisbare, dynamische Gestalt. Sie rollen nicht stückhaft ab, als ob ihre Phasenfolge aus einzelnen Elementen assoziiert wäre, bilden kein Zeitmosaik, sondern eine gewisse Ganzheit ist vorgegeben, innerhalb deren die einzelnen Bewegungskurven variieren. [...] Infolgedessen sind die Bewegungsgestalten bildhaft, wenn auch über eine gewisse Zeitdauer erstreckt, dem Beobachter gegenwärtig. ${ }^{73}$

Für Plessner ist die Ausdrucksbewegung (von der er auch als Bewegungsbild spricht) jene Dimension von Bewegung, in der sich die „Schicht des Verhaltens“ zeigt. Mit dieser Schicht zielt Plessner auf eine „Sphäre gegensinnig aufeinander bezogener, subjektiv-objektiv, bildhaft-sinnhaft, psychophysisch indifferenter Gestaltcharaktere, in denen das Benehmen sich abspielt“, ${ }^{74}$ d. h. eine Sphäre, in der sich eine „ursprüngliche Identität von Anschaulichkeit und Verständlichkeit auf Grund des Formcharakters der Bewegungsgestalten“ ereignet. ${ }^{75}$ Plessners

72 Helmuth Plessner: Die Deutung des mimischen Ausdrucks. Ein Beitrag zur Lehre vom Bewußtsein des anderen Ichs (verfasst in Zusammenarbeit mit Frederik Jacobus Johannes Buytendijk) [1925]. In: Helmuth Plessner. Gesammelte Schriften, Vol. 7: Ausdruck und menschliche Natur. Hrsg. v. Günther Dux, Odo Marquard und Elisabeth Ströker. Frankfurt a. M.: Suhrkamp 1982, S. 67-129, hier S. 78.

73 Ebd., S. 77f. Zu einer solchen Auffassung von Bewegung in der aktuellen phänomenologisch geprägten Embodiment-Forschung vgl. auch Maxine Sheets-Johnstone: The Primacy of Movement. 2., erweiterte Auflage. Amsterdam: John Benjamins 2011.

74 Plessner: Die Deutung des mimischen Ausdrucks, S. 125.

75 Ebd., S. 83. Vgl. zu Plessners Begriff einer Schicht des Verhaltens, die für sein Verständnis einer sich im Vollzug herstellenden leiblichen Intersubjektivität wesentlich ist, auch Thorsten Kubitza: Identität - Verkörperung - Bildung. Pädagogische Perspektiven der Philosophischen Anthropologie Helmuth Plessners. Bielefeld: transcript 2005, hier S. 205-226. Plessner steht hier Merleau-Pontys Idee des Chiasmus als einer „zwischenleibliche[n] Verflechtung“ nahe, wie es bei Bernhard Waldenfels heißt (Bernhard Waldenfels: Emmanuel Levinas: Verflechtung und Trennung. Wege zwischen Merleau-Ponty und Levinas. In: Deutsch-französische Grenzgänge. Frankfurt a. M.: Suhrkamp 1995, S. 346-382, hier S. 358, Herv. i. O.). Auch Merleau-Ponty begreift Gestik und Mimik als intersubjektives, emotional-affektives Ausdrucks- und Wahrnehmungsgeschehen: „Tatsächlich verstehen kleine Kinder Gesten und Gesichtsausdruck, lange bevor sie fähig sind, sie aus sich selbst hervorzubringen; also muß der Sinn dieser Verhaltensweisen gleichsam mit ihnen 
Überlegungen harmonieren insofern mit dem oben skizzierten Konzept des Performativen, denn Ausdruck erschließt sich also gerade nicht im „Lesen zeichenhafter Bedeutung“, sondern ist verständlich im „Vollzug der Wahrnehmung im Angesicht“ des Verhaltens. ${ }^{76}$ Und mehr noch: Die Materialität der Kommunikation im Sinne der spezifischen Ausdrucksmöglichkeiten eines Verhaltens sind von unmittelbarer Signifikanz. So heißt es bei Plessner:

Diese Durchdringung von seelischem Gehalt und körperlicher Ausdruckserscheinung ist dann so vollkommen, daß es unmöglich wird, den Gehalt eines Affekts, einer Stimmung, Gesinnung und Neigung ganz für sich und ohne die nun einmal in der Organisation des Körpers gegebenen Ausdrucksmöglichkeiten zu erfassen. ${ }^{77}$

Zugespitzt formuliert, verschiebt sich durch eine ausdruckstheoretische Perspektive das Interesse an Bewegung vom „Was“ zum „Wie“. Es ist dies eine Verschiebung, wie sie beispielsweise bei Plessner in seiner Unterscheidung von „Handlungsbild“ und „Ausdrucksbild“ gegeben ist, ${ }^{78}$ oder von Karl Bühler in seiner Ausdruckstheorie mit Blick auf die Geste angesprochen wird: „[W]arum sollen z. B. gestenhaft malende Hände nicht imstande sein, das eine Mal frisch und froh, ein zweites Mal wütend, ein drittes Mal zögernd und erschreckt den Akt des Zeichnens durchzuführen?“79 Und auf eine ebensolche Fokusverlagerung vom Was zum Wie spitzt auch Stern seine Ausführungen zu den „dynamische[n] Vitalitätsformen“, ${ }^{80}$ mit denen er ein zentrales Moment menschlichen Erlebens zu fassen sucht.

verwachsen sein. An dieser Stelle müssen wir das Vorurteil zurückweisen, das aus Liebe, Haß oder Zorn ,innere Wirklichkeiten' macht, die nur demjenigen als dem einzigen Zeugen zugänglich sind, der sie empfindet. Zorn, Scham, Haß, Liebe [...] sind von außen sichtbare Weisen des Verhaltens. Sie sind auf dem Gesicht oder in den Gesten und nicht hinter ihnen verborgen.“ (Merleau-Ponty: Das Kino und die neue Psychologie, S. 75, Herv. i. O.)

76 Morsch: Wahrgenommene Wahrnehmung, gesehenes Sehen, S. $254 \mathrm{f}$.

77 Plessner: Lachen und Weinen, S. 260. Entsprechend ist also der „Affektgehalt [...] nicht von den Ausdrucksorganen zu trennen, er ist nicht etwas hinter diesem Liegendes, sondern eine nur in diesen Artikulationsbedingungen sich ausprägende Qualität“, wie Greifenstein resümiert (Greifenstein: Tempi der Bewegung - Modi des Gefühls (Manuskriptfassung), S. 148).

78 Vgl. Plessner: Die Deutung des mimischen Ausdrucks, S. 89-93 Kappelhoff spricht in Rückbezug auf Plessner entsprechend auch von der Ausdrucksbewegung als dem, was das „Figurative an einer Aktion“, die „gestische Formschicht der organischen Bewegung“ bezeichnet (Kappelhoff: Matrix der Gefühle, S. 152).

79 Bühler: Ausdruckstheorie, S. 39.

80 Mit dem Begriff der ,dynamischen Vitalitätsformen' fasst Stern jene Termini zusammen, anhand derer er sich vormals - jeweils mit Betonung wechselnder konzeptueller Kontexte - mit den dynamischen Aspekten menschlichen Erlebens auseinandergesetzt hat: ,Vitalitätsaffekte‘, 


\begin{tabular}{lll}
\hline explodierend & aufwallend & akzelerierend \\
\hline anschwellend & aufberstend & verblassend \\
\hline lang gezogen & verschwindend & flüchtig \\
\hline energisch & kraftvoll & schwach \\
\hline ansteigend & pulsierend & zögerlich \\
\hline eilend & mitziehend & schiebend \\
\hline entspannend & schmelzend & schwebend \\
\hline aufgeregt & angestrengt & mühelos \\
\hline angespannt & sanft & stockend \\
\hline gleitend & schwingend & gestrafft \\
\hline stillhaltend & locker & gefesselt \\
\hline & & und viele mehr \\
\hline
\end{tabular}

Abb. 8: Daniel Sterns Liste beispielhafter amodaler Qualitäten, die von Stern als dynamische Vitalitätsformen konzeptualisiert werden. ${ }^{81}$

So kommentiert er eine Auflistung von Worten wie „explodierend“, „eilend“, „schwebend“, „verblassend“, „pulsierend“, „stillhaltend“, „kraftvoll“, „stockend“ (vgl. Abb. 8) folgendermaßen:

Obwohl diese Wörter durchaus geläufig sind, ist die Liste dennoch merkwürdig. Bei den meisten Wörtern handelt es sich um Adverbien oder Adjektive, nicht um Wörter für Emotionen. Die Begriffe bezeichnen auch weder motivationale Zustände noch reine Wahrnehmungen oder körperliche Sensationen im strengen Sinn, denn sie implizieren keine Sinnesmodalität. Sie benennen auch keine direkten Kognitionen, so wie man den Begriff gewöhnlich versteht, und keine Aktionen, denn sie verweisen weder auf einen Zielzustand noch auf spezifische Handlungsmittel. Die Wörter zielen auf irgendetwas zwischen all dem. Gefühltes Erleben von Kraft - in Bewegung - mit einer zeitlichen Kontur, einem Gewahrsein von Lebendigkeit, ein Gefühl, irgendwohin zu gehen. Nicht spezifische Inhalte sind angesprochen, sondern eher Formen. Die Wörter betreffen das ,Wie', die Art und Weise, den Stil, nicht das ,Was‘ oder das ,Warum‘. Ungeachtet des ,Inhalts‘ (Gedanken, Aktivitäten, Emotionen) hat jede dieser Vitalitätsgestalten ihr eigenes Fließmuster (zum Beispiel akzelerierend, explodierend und verblassend), das eine besondere Art des Erlebens konstituiert. “82

,temporale Gefühlsgestalten` bzw. ,zeitliche Gefühlsformen‘, ,temporale Gefühlskonturen‘, ,proto-narrative Hüllen' bzw. ,Vitalitätskonturen'. Vgl. Stern: Ausdrucksformen der Vitalität, S. $16 \mathrm{f}$.

81 Ebd., S. 17.

82 Ebd., S. 18, Herv. CS. 


\section{Rückkopplung I: Differenzen des Kinästhetischen in KMT und Ausdruckstheorie}

[...] movement is an ongoing spatio-temporal-energic dynamic that is first of all felt as such. ${ }^{83}$

An dieser Stelle sei innegehalten und der gedankliche Bogen noch einmal kritisch zurück zur Konzeptuellen Metapherntheorie geschlagen. Denn das Überschreiten einzelner Sinnesmodalitäten und die Idee des Gestalthaften - beides ist für die Ausdruckstheorie (ob nun mit dem Begriff ,Bewegungsbild', ,Ausdrucksbewegung، oder ,dynamische Vitalitätsform‘ bzw. ,Vitalitätsaffekt') wesentlich -, gibt zunächst einmal Anlass zu der Vermutung, dass sich darin ein verbindendes Moment zum Image-Schema-Konzept der KMT auftut (wie es in Kapitel 2 dargelegt wurde). Tatsächlich kommt beispielsweise Johnson in The Meaning of the Body im Zuge seiner Auseinandersetzung mit Image-Schemata auch auf Sterns Vitalitätsaffekte zu sprechen. ${ }^{84}$ Und Johnsons Stern-Lektüre wird in der Folge in der kognitiv-linguistischen Literatur so rezipiert, dass Image-Schemata „patterns of feelings“ wären. ${ }^{85}$ Allerdings mutet eine Einverleibung der Stern'schen Affektkonturen in das Konzept des Image-Schemas, wie es die Kognitive Linguistik hervorgebracht hat, fragwürdig an. Dem gehe ich hier über eine Auseinandersetzung mit dem Begriff des Kinästhetischen nach, mit dem die KMT ihr Konzept des Image-Schemas gelabelt hat. Der kognitionspsychologischen KMT-Auffassung des Kinästhetischen wird dabei mit Bezug auf die Philosophin Maxine Sheets-Johnstone eine phänomenologische Replik gegeben.

83 Sheets-Johnstone: The Primacy of Movement, S. 511.

84 Johnson: The Meaning of the Body, S. 135-154, hier insb. S. 143f. Vgl. zu Stern bei Johnson auch ebd., S. 41-45.

85 Mit einer solchen Gleichsetzung wird Johnsons Auseinandersetzung mit Stern etwa bei Rohrer ausgelegt (Rohrer: Embodiment and Experientialism, S. 35f.). Eine Überlagerung von ImageSchema und Vitalitätsaffekt ist auch in einer früheren Auseinandersetzung Johnsons mit Stern angelegt: „Stern's account of both amodal perception and vitality affects has close parallels with the account of ,image schemas' in second-generation cognitive science. [...] What Stern's account of vitality affects adds to the concept of an image schema is the crucial affective dimension that orients, motivates, and gives force to our conceptual thinking. Vitality affects give flesh and blood to our more skeletally defined image schemas, thereby giving substance and life to our theory of embodied imaginative structures of human understanding. This also allows us to understand why image schemas are so important to our sense of our world and ourselves, and it explains why they can have the emotional and motivating force they have." (Mark Johnson: Embodied Reason. In: Perspectives on Embodiment. The Intersections of Nature and Culture. Hrsg. v. Gail Weiss. New York: Routledge 1999, S. 81-102, hier S. 93, Herv. CS.) 
In seiner Beschäftigung mit Stern weist Johnson selbst auf eine Differenz zwischen image-schematischen Strukturmustern sensomotorischer Erfahrung und den affektiven Erfahrungsqualitäten konkreter Situationen hin. Letztere werden als eine theoretische wie auch deskriptive Leerstelle im Konzept des ImageSchemas, wie es die KMT eingeführt hat, identifiziert:

[...] there is a ,down side‘ to our standard way of describing image schemas. The character of image-schematic analysis that has always worried me since its inception is its exclusive focus on recurring structures or patterns of organism-environment sensory-motor interactions. In short, if you attend only to structure, you necessarily ignore the nonstructural, more qualitative aspects of meaning and thought. You are left with a skeletal structure without the flesh and blood of embodied understanding. You lose, or at least overlook, the very thing that gives image schemas their life, motivating force, and relevance to human meaning, namely, their embeddedness within affect-laden and value-laden experience. There may be no way around this problem, but we can at least recognize what is left out of our theory, without which image schemas could not play their crucial role in conceptualization and reasoning. [...] the limitations of our exclusively structural analysis of image schemas leave out something of great importance. Conscious life is very much an affair of felt qualities of situations. The human experience of meaning concerns both structure and quality. [...] When we describe the image-schematic structure alone, we never capture fully the qualities that are the flesh and blood of our experience. ${ }^{86}$

Bereits hierin zeigt sich, dass die Konzepte ,Ausdrucksbewegung und ,ImageSchema' also keinesfalls gleichzusetzen sind. Die Unterschiedlichkeit klingt denn auch in einer Bemerkung Johnsons zur Vielschichtigkeit von Bewegung an, in der (ohne dass Plessner für Johnson eine direkte Bezugsfolie wäre) Plessners Betrachtung des Gehens als einem Ausdrucksbewegungsbild sowie Sterns Vitalitätsaffekte Resonanz findet:

[...] movements are not defined merely by the internal structure of image schemas, but also by their distinctive qualities. For example, my movement along a forest path is not defined only by the source-path-goal structure of my walking. In addition, my movement manifests dynamic qualities - it can be, for example, explosive, graceful, halting, weak, or jerky. ${ }^{87}$

Der Konzeptuellen Metapherntheorie, so ließe sich sagen, geht es um Schemata als Kondensate von Bewegungs-Erfahrung - um eine sich wiederholende Erfahrung mit Bewegung in einem funktionalen, zielorientierten Handlungskontext gewissermaßen. Es geht um Schemata, die sich beliebig manifestieren können, die sich wesentlich durch ein Moment der Abstraktion bestimmen. Der Aus-

86 Johnson: The Philosophical Significance of Image Schemas, S. 27 f., Herv. i. O.

87 Johnson: The Meaning of the Body, S. 21, Herv. i. O. 
druckstheorie (der im Kontext der vorliegenden Arbeit die Überlegungen Sterns hinzugerechnet werden) hingegen geht es um Spezifika von BewegungsErfahrung - um eine Erfahrung von Bewegung, durch die immer situativ verortet zu verstehende, an eine Materialität, an die Artikulation gebundene Ausdrucksdimension. Das Wesen des Ausdrucks ist an die konkrete Situation gebunden, in der die Bewegungsqualitäten zur Anschauung kommen, indem sich das Erleben einer zeitlichen Figuration realisiert. Die Expressivität, eine Ausdrucksbewegung, eine affektive Qualität ist nicht von ihrer Artikulation, nicht vom affektiven Erleben abstrahiert zu denken. Es geht um ein qualitatives, affektives, verkörpertes Erleben einer spezifisch artikulierten Figuration von Raum und Zeit; um ein subjektives Herstellen von Welt, das zugleich immer schon als Intersubjektivität zu denken ist. Wenn also im Rahmen ausdruckstheoretischer Überlegungen von Bewegung und Wahrnehmung die Rede ist, dann zielt dies nicht auf ein abstrahiertes Struktur-Kondensat von (zurückliegender) körperlich-motorischer Erfahrung von gegebenen Subjekten, wie dies die KMT in ihrer Suche nach Elementen eines postulierten konzeptuellen Systems tut.

Die Differenz lässt sich am jeweiligen Kinästhetik-Verständnis weiter verdeutlichen. Wie oben bereits angeführt, ordnet die KMT ihr Konzept der Image-Schemata (d. h. Strukturen verkörperter Erfahrungen, wie sie mit Bewegungen einhergehen, insofern den Schemata sich wiederholende körperliche Bewegungen des Menschen durch einen Raum, sogenannte Wahrnehmungsinteraktionen sowie Manipulationsweisen von Objekten zugrunde liegen) der Kinästhetik zu. Das Kinästhetische wird von der KMT dabei als etwas definiert, das ein von bestimmten Sinnesmodalitäten unabhängiges Bewusstsein von verschiedenen Aspekten eines „functioning in space“ umfasst (Orientierung, Bewegung, Balance, Gestaltbeurteilung usw.). ${ }^{88}$ Damit vertritt die KMT ein kognitionspsychologisches KinästhetikKonzept, wie es etwa Jan Restat beschreibt. Restat sieht in der kognitiven Kinästhetik eine Wissensart, die die „modale Grundlage der amodalen Raumkognition“ ist. ${ }^{89}$ Ihm zufolge kann Kinästhetik als unsere „Sinnesmodalität zum Spüren unserer Körperhaltung, Körperbewegung und körperlichen Anstrengung“ aufgefasst werden, „die hauptsächlich auf Muskelrezeptoren“ beruht und aufgrund derer wir

in der körperlichen Interaktion mit der Umwelt [...] viele physikalische Eigenschaften von Objekten wie ihr Gewicht, ihre Beweglichkeit, Schwergängigkeit, ihren räumlichen Ort u. a. m. spüren [können]. [...] [D]ie kinästhetische Modalität [stellt] unser Wahrnehmungsfenster

88 Lakoff: Women, Fire, and Dangerous Things, S. $445 \mathrm{f}$.

89 So der Untertitel zu seiner 1999 erschienenen Publikation zur kognitiven Kinästhetik. 
in die mechanische physikalische Beschaffenheit unserer Welt (Raum, Zeit, Kraft und Kausalität) dar[...]. ${ }^{90}$

In einem solchen Sinne interessiert sich die KMT mit dem Kinästhetischen also für ein Funktionieren und Orientieren im physikalisch verstandenen Raum. (Es sei daran erinnert, dass auch das Konzept der Primärmetaphern einen Erfahrungsbegriff im Kontext zielorientierter Handlungen eines Menschen in einer gegebenen Umwelt adressiert.)

Mit Maxine Sheets-Johnstone lässt sich dem nun ein anders gelagertes, mit dem ausdruckstheoretischen Bewegungsverständnis harmonierendes Kinästhetik-Verständnis entgegenstellen. ${ }^{91}$ Sheets-Johnstone proklamiert (vor allem im Rückgang auf Edmund Husserl) den Begriff des Lebendigen (animation). ${ }^{92}$ Das Lebendige denkt sie dabei unmittelbar mit einem dynamischen Bewegungsverständnis zusammen:

A phenomenological investigation of movement discloses qualitative dimension of movement that testify to movement being a dynamic phenomenon, and being a dynamic, it is: (1) falsely defined a change in position, (2) falsely specified in terms of sensations, and (3) inaccurately described as simply taking place in space and in time. ${ }^{93}$

90 Jan Restat: Kognitive Kinästhetik. Die modale Grundlage der amodalen Raumkognition. Lengerich: Pabst 1999, Klappentext.

91 Im Übrigen nimmt Sheets-Johnstone bei Johnsons Buch The Meaning of the Body eine prominente Stellung ein, eröffnet er doch sein erstes Kapitel „The Movement of Life“ mit einem Referat zu Sheets-Johnstone (auch seine oben zitierte Überlegung zu den dynamischen Bewegungsqualitäten des Gehens ist diesem Kontext entnommen). Letztlich bleibt dies jedoch ohne grundlegende Konsequenz für das Modell der Konzeptuellen Metaphern.

92 Sheets-Johnstone distanziert sich damit von Teilen des gegenwärtigen kognitionswissenschaftlich informierten, zeitgenössisch-phänomenologischen Diskursstrang um Embodiment/ Verkörperung, insofern sie den Begriff der Verkörperung als missverständlich, ungenügend und irreführend erachtet (vgl. z. B. Maxine Sheets-Johnstone: Body and Movement. Basic Dynamic Principles. In: Handbook of Phenomenology and Cognitive Science. Hrsg. v. Shaun Gallagher und Daniel Schmicking. Dordrecht [u.a.]: Springer 2010, S. 217-234, hier S. 219-221; siehe auch Sheets-Johnstone: The Primacy of Movement, S. 309-313, 453-475). So heißt es etwa in The Primacy of Movement (ebd., S. 312): „Embodiment fails to do justice to animate form; it fails to recognize the primacy of movement and its dynamic tactile-kinesthetic-kinetic correlates. When we have recourse to ,embodiment', we avoid coming to terms with bodies, with what is actually there, sensuously present in our experience, precisely as with the experience of moving and changing shape - or with the experience of a front and a back and of moving more easily forward than backward." Hinsichtlich der zeitgenössischen Phänomenologie sind vor allem die Arbeiten Shaun Gallaghers, die im Zentrum ihrer Kritik stehen, insofern kinästhetische Erfahrung dort auf ein positionales Körperwissen reduziert wird (siehe ebd., S. 512) und dadurch entdynamisiert ist. 93 Sheets-Johnstone: Body and Movement, S. 222. 
Es ist Sheets-Johnstone zufolge also eine phänomenologische Betrachtung, mit der das alltägliche Bewegungsverständnis, wie es auch der KMT zu eigen ist, konterkariert wird. Denn dann erschließt sich Bewegung wie folgt: „(1) movement is not a change of position, but the dynamic reality of the kinetic change itself; (2) movement is a matter not of sensations but of a felt qualitative dynamic [...]; (3) any movement creates its own time, space, and force, and thereby its own particular dynamic."94 Die qualitativen Dimensionen, über die sich Bewegung phänomenologisch erschließen lässt - „,t]ensional, linear, areal, and projectional qualities“95 - sind dabei nur analytisch, nicht jedoch im Erleben separierbar: „they are always integral parts of a whole kinetic dynamic“. 96 Damit schließt Sheets-Johnstone unmittelbar an Stern an, demzufolge - wie oben bereits ausgeführt - in den kinetischen Gestalten, die sich im Verhalten zeigen und dieses gestalten, die Aspekte „Bewegung, Zeit, Kraft, Raum und Intention/Gerichtetheit“97 nur theoretisch separierbar sind, da sie im Wahrnehmungserleben zu „Ganzheiten oder Gestalten und emergenten Eigenschaften“ verschmelzen. ${ }^{98}$ Und eben an ein solches Bewegungsverständnis koppelt Sheets-Johnstone auch ihren Begriff der Kinästhesie: „kinesthesia [...] [is, CS] a matter [...] of an unfolding qualitatively felt kinetic dynamic“.99

Nun hat Stern emphatisch konstatiert, „dass die dynamischen Formen der Vitalität die Fundamentalsten [sic] aller gefühlten Erfahrungen sind, wenn wir mit anderen ,Menschen in Bewegung“ zu tun haben“. ${ }^{100}$ Doch zugleich weist er darauf hin, dass diese amodalen kinetischen Gestalten nicht nur relevant für menschliches Verhalten sind: „Zeitkonturen und Vitalitätsaffekte sind Teil all unserer Wahrnehmungen, gleichgültig, ob es sich um alltägliche oder um ästhetische Eindrücke handelt““ ${ }^{101}$ Insbesondere die zeitbasierten Künste sind es, an die Stern hier denkt: Musik, Tanz - und Film. ${ }^{102}$

94 Ebd., S. 225, Herv. CS.

95 Ebd., S. 222.

96 Ebd.

97 Stern: Ausdrucksformen der Vitalität, S. 13.

98 Ebd., S. 14.

99 Sheets-Johnstone: Body and Movement, S. 229.

100 Stern: Ausdrucksformen der Vitalität, S. $18 \mathrm{f}$.

101 Daniel N. Stern: Der Gegenwartsmoment. Veränderungsprozesse in Psychoanalyse, Psychotherapie und Alltag [2004]. Frankfurt a. M.: Brandes \& Apsel 2005, hier S. 85.

102 Vgl. Stern: Ausdrucksformen der Vitalität, S. 15. 


\section{Filmische Expressivität (Kappelhoff) - ein Gestikulieren von vERTIGo wahrnehmen}

In der Tat (ohne allerdings, dass damit einer Anthropomorphisierung des Films das Wort geredet und Filmwahrnehmung und Alltagswahrnehmung einander schlicht gleichgesetzt wären) ${ }^{103}$ ist die Idee der Ausdrucksbewegung, die Idee einer zeitlichen Figuration ein zentraler Bezugspunkt für die klassische und später dann auch für die moderne Filmtheorie - und zwar bei der Frage nach dem emotionalen Vermögen filmischer Bilder.

So legt Hugo Münsterberg eine wahrnehmungspsychologische Filmtheorie vor (1916), ${ }^{104}$ „,die [...] die Verschränkung von zeitlich entfalteter Bewegung und emotionalem Erleben zur affektiven Dimension des Kinos erklärt“ - und damit „die Loslösung des Begriffs der Ausdrucksbewegung vom menschlichen Körper vorweg[nimmt], wie sie Helmuth Plessner neun Jahre später in seinen Ausführungen zu ,Bewegungsbildern“ vollzieht““ ${ }^{105}$ Bei Béla Balázs findet sich dieser Gedanke in seinen Überlegungen zur Großaufnahme und dem filmischen Bild als Gefühlsakkord (1924). ${ }^{106}$ Bei Sergej Eisenstein lässt sich diese Idee bei seinen Ausführungen zu den vier Dimension des Films verfolgen (1929), die er im Rahmen seines in der Montage gründenden Verständnisses des filmischen Bewegungsbildes entwickelt, ${ }^{107}$ „,das immer schon beides, Leinwandbild und Zuschau-

103 Eine solche Gleichsetzung ist der zentrale Vorwurf, der der Filmphänomenologie Sobchacks entgegengebracht wird. Für eine Rekonstruktion der wesentlich deleuzianisch geprägten Kritik an Sobchack vgl. Drehli Robnik: Körper-Erfahrung und Film-Phänomenologie. In: Moderne Film Theorie. Hrsg. v. Jürgen Felix. Mainz: Bender 2002, S. 246-280; Morsch: Medienästhetik des Films, S. 278-294; Anke Zechner: Die Sinne im Kino. Eine Theorie der Filmwahrnehmung. Frankfurt a. M./ Basel: Stroemfeld 2013, hier S. 223-251. Deleuze kritisiert, die Phänomenologie erhebe die ,natürliche Wahrnehmung، und ihre Bedingungen zur Norm (vgl. Gilles Deleuze: Über Das Bewegungsbild [1983]. In: Unterhandlungen. 1972-1990. Frankfurt a. M.: Suhrkamp 1993, S. 70-85, hier S. 72). Auf eine Differenz hingegen weist etwa auch Rudolf Arnheim hin (Rudolf Arnheim: Weltbild und Filmbild [1932]. In: Film als Kunst. Mit einem Vorwort zur Neuausgabe. Frankfurt a. M.: Suhrkamp 1974, S. 19-47).

104 Hugo Münsterberg: Das Lichtspiel. Eine psychologische Studie (1916) und andere Schriften zum Kino. Jörg Schweinitz. Wien: Synema 1996.

105 Kappelhoff/Bakels: Das Zuschauergefühl, S. 84.

106 Béla Balázs: Der sichtbare Mensch oder die Kultur des Films [1924]. In: Béla Balász. Schriften zum Film, Vol. 1. Hrsg. v. Helmut H. Diederichs, Wolfgang Gersch und Magda Nagy. Budapest/ München/Berlin: Hanser 1982, S. 43-143. Vgl. auch Hermann Kappelhoff: Unerreichbar, unberührbar, zu spät. Das Gesicht als kinematografische Form der Erfahrung. In: montage AV 13.2 (2004), S. 29-53.

107 Eisenstein: Die vierte Dimension im Film. Vgl. zu Eisensteins Konzeption des Bewegungbildes und dessen vier Montagedimension (metrische, rhythmische, tonale Montage und Oberton- 
erwahrnehmung, in sich einschließt“ “ ${ }^{108}$ Auch die Überlegungen Merleau-Pontys, die er dem Film gewidmet hat (1947), sind hier zu nennen. Vor dem Hintergrund, dass Merleau-Ponty Emotion nicht als „psychische und innere Tatsache“ fasst, sondern als eine im wahrnehmbaren Ausdruck gegebene „Veränderung unserer Beziehungen zum anderen und zur Welt“"109 (etwa durch Gesten), wird die Ausdruckshaftigkeit der zeitlichen Formen hervorgehoben, mit denen ein Film sich zeigt. Prominent ist natürlich Gilles Deleuzes Konzept des Affektbildes (1983), wie er es in seinem Kinobuch zum Bewegungs-Bild entworfen hat. Mit dem Affektbild zielt Deleuze, der den Zuschauer in gewisser Weise in das Bild hineindenkt, auf einen spezifischen kinematografischen Bildtyp, für den die Bewegungsdynamik des menschlichen Gesichts (,Ein Affektbild ist eine Großaufnahme, und eine Großaufnahme ist ein Gesicht." $)^{110}$ wie auch auf die Ausdrucksgebundenheit abgehoben wird (,Der Affekt existiert nicht unabhängig von etwas, das ihn ausdrückt [...]. Was ihn ausdrückt, ist ein Gesicht, das Äquivalent eines Gesichts [...] oder sogar ein Satz [...].“). ${ }^{111}$ In Abgrenzung zum kognitionspsychologischen Konzept distinkter Emotionen führt Raymond Bellour für sein Verständnis filmischer Emotion Deleuzes Denken mit Sterns Konzept der Vitalitätsaffekte zusammen (2002); ${ }^{112}$ Hermann Kappelhoff wiederum hat das Konzept der filmischen Aus-

montage) auch Hermann Kappelhoff: Die vierte Dimension des Bewegungsbildes. Das filmische Bild im Übergang zwischen individueller Leiblichkeit und kultureller Fantasie. In: Audiovisuelle Emotionen. Emotionsdarstellung und Emotionsvermittlung durch audiovisuelle Medienangebote. Hrsg. v. Anne Bartsch, Jens Eder und Kathrin Fahlenbrach. Köln: Herbert von Halem 2007, S. 297311.

108 Kappelhoff: Ausdrucksbewegung und Zuschauerempfinden, S. 80. Bei Eisenstein begegnet einem auch das Konzept der Amodalität, wenn es mit Blick auf die Obertonmontage etwa heißt: „Für den musikalischen Oberton [...] ist der Ausdruck ,Ich höre‘ eigentlich schon unzutreffend. Ebenso für den visuellen ein ,Ich sehe‘. Für beide gilt nunmehr die neue Simultanformel: ,Ich nehme wahr، “ (Eisenstein: Die vierte Dimension im Film, S. 118.)

109 Merleau-Ponty: Das Kino und die neue Psychologie, S. 76.

110 Deleuze: Das Bewegungs-Bild, S. 123, Herv. i. O.

111 Ebd., S. 136. Vgl. zu Deleuze auch Hermann Kappelhoff: Empfindungsbilder. Subjektivierte Zeit im melodramatischen Kino. In: Zeitlichkeiten - Zur Realität der Künste. Hrsg. v. Theresia Birkenhauer und Anette Storr. Berlin: Vorwerk 8 1998, S. 93-119; Hermann Kappelhoff: Bühne der Emotionen, Leinwand der Empfindung. Das bürgerliche Gesicht. In: Blick, Macht, Gesicht. Hrsg. v. Helga Gläser, Bernhard Groß und Hermann Kappelhoff. Berlin: Vorwerk 8 2001, S. 9-41; Hermann Kappelhoff/Sarah Greifenstein: Feeling Gloomy or Riding High. Timings of Melodrama and Comedy. In: Timing of Affect. Epistemologies, Aesthetics, Politics. Hrsg. v. Marie-Luise Angerer, Bernd Bösel und Michaela Ott. Zürich/Berlin: diaphanes 2014, S. 263-282.

112 Raymond Bellour: Das Entfalten der Emotionen [2002]. In: Kinogefühle. Emotionaliät und Film. Hrsg. v. Matthias Brütsch, Vinzenz Hediger, Ursula von Keitz und Margit Tröhler. Marburg: Schüren 2005, S. 51-102. Bellour (wie auch Sobchack) entwickelt dabei eine Idee des Körpers des Films (oder vom Film als Körper), ,which goes beyond any psychologically grounded attention to 
drucksbewegung seit den 1990er Jahren nicht nur maßgeblich historisch wie theoretisch ausgeleuchtet, ${ }^{113}$ sondern auch filmanalytisch mit Blick auf ein „Zuschauergefühl“"114 perspektiviert. $^{115}$

Mit einer Hinwendung zur filmischen Ausdrucksbewegung tritt nun gerade jener Aspekt, der für den funktionalen Erfahrungsbegriff der KMT im Vordergrund steht, ${ }^{116}$ in den Hintergrund: die Bewegung von Objekten oder Menschen von einer Position A zu einer Position B innerhalb eines Raumes. Beim Film ist mit solchen Bewegungen, so Kappelhoff,

die Ebene beschrieben, auf der das filmische Bild eine Repräsentation von Objekten, von Dingen und Menschen in einem Raum bezeichnet, der präzise unserer alltäglichen Wahrnehmungswelt entspricht. Bewegung meint hier Verlagerung der Stellungen sich bewegender Objekte in einem gegebenen Raum. [...] In dieser Perspektive ist das filmische Bild eng mit unserer Alltagswahrnehmung verschränkt. Beide - filmische Bewegung und alltägliche Wahrnehmung - beziehen sich auf einen Raum als ein Orientierungssystem, das jeder

the tactile and other somatic aspects of film viewing as an individual and individually attributable experience“, so Vinzenz Hediger in seiner Hinführung zu Christiane Voss: Film Experience and the Formation of Illusion. The Spectator as ,Surrogate Body ${ }^{\star}$ for the Cinema. In: Cinema Journal 50.4 (2011), S. 136-150, hier S. 137.

113 Vgl. z. B. Kappelhoff: Empfindungsbilder; Kappelhoff: Matrix der Gefühle; Kappelhoff: Ausdrucksbewegung und Zuschauerempfinden; Kappelhoff/Greifenstein: Feeling Gloomy or Riding High.

114 Kappelhoff/Bakels: Das Zuschauergefühl.

115 Abzugrenzen sind solche Ansätze, wie sie im oben stehenden Absatz von Münsterberg bis Kappelhoff aufgerufen wurden, von Modellen, die der kognitiven Filmtheorie zugehörig sind und in repräsentierten Figurenhandlungen und Plotentwicklungen das entscheidende emotionale Moment sehen (Tan: Emotion and the Structure of Narrative Film; Torben K. Grodal: Embodied Visions. Evolution, Emotion, Culture and Film. Oxford: Oxford University Press 2009; Carl R. Plantinga: Emotion and Affect. In: The Routledge Compagnion to Philosophy and Film. Hrsg. v. Paisley Livingston und Carl R. Plantinga. Abingdon/Oxon: Routledge 2009, S. 86-96): „These cognitively orientated theories conceptualize the spectator's reactions to a film predominantly as a conscious activity, which is controlled by mental operations of hypothesizing and constructing schemata. Whether a spectator finds a character on screen likeable or not, feels with him or not, is assumed to be dependent on the cognitive evaluation of a narrative situation. In short terms, these theories regard the narration as predominant, while aesthetics seem to be only subsidiary means. [...] Thusly, film aesthetics are either regarded as supporting means - as secondary stylistic or technical tools - or as cognitively evaluated aesthetic moments that stand out from the narration. What remains mainly unconsidered in such an approach, is the way spectators experience film images affectively, bodily, and as well unconsciously." (Scherer/Greifenstein/Kappelhoff: Expressive Movements in Audiovisual Media, S. 2082.) Es bleibt auch unberücksichtigt, inwieweit diese Dimension in Prozesse des meaning-making involviert ist.

116 Vgl. hierzu die Ausführungen zu Image-Schemata und Primärmetaphern in der vorliegenden Studie. 
Bewegung, die wir sinnlich erfassen, notwendig vorausliegt. Man kann in diesem Sinn von einem apriorisch gegebenen Raum sprechen. ${ }^{117}$

Doch audiovisuelle Bilder sind eben nicht einfach Repräsentationen gegebener Räume. Vielmehr bringen sie selbst noch Zeit und Raum hervor - eben darauf hebt die Rede von einer filmischen Expressivität ab. Es entsteht ein „Bildraum“ (Kappelhoff) - ein Raum, der in einer in der Darstellungsform selbst liegenden Bewegung gründet:

[Es] formieren sich rhythmische Bewegungsmuster, die eine eigene Dimension des filmischen Bildes bezeichnen. Der Raum ist hier keine apriorische Gegebenheit mehr, er hat auch keine Verbindung zum Raum alltäglicher Wahrnehmung: Die räumlichen Koordinaten unserer Wahrnehmung sind vielmehr selbst zum Bestandteil einer Bewegungsfiguration, zum Material filmischer Inszenierung geworden. Der Raum ist selbst eine Funktion von Kameraarbeit, Montage und szenischer Komposition: Er ist ein Raumkonstrukt, ein Raumbild, ein Raumeffekt. ${ }^{118}$

\section{Kappelhoff resümiert daher:}

So gesehen vollzieht sich die Bewegung des kinematografischen Bildes in drei Dimensionen, in der äußeren Bewegung des Dargestellten (die Bewegung dargestellter Objekte im Raum), in der inneren Bewegung des audiovisuellen Bilds (die Zeit des sich entfaltenden Films) und in der Übertragung der Bewegung des sich entfaltenden Films auf die Empfindungsbewegung des Zuschauers (der Prozess der Verinnerlichung). ${ }^{119}$

Mit dem emergierenden „Bildraum“ ist von Kappelhoff daher die Ausdrucksebene, die Ausdrucksbewegung als Dimension des filmischen Bildes im Sinne einer sich darbietenden Wahrnehmungssituation benannt. Das damit verbundene Bewegungsverständnis liegt jenseits einer mechanistischen Betrachtung von Film als einem objekthaften Bewegtbildmedium und geht auch nicht einfach in einem repräsentationalen Zugang zu Bewegung auf. Mit der filmischen Ausdrucksbewe-

117 Kappelhoff: Ausdrucksbewegung und Zuschauerempfinden, S. 74. Zur Erinnerung: Die Ebene eines gegebenen Raumes ist auch für Coëgnarts und Kravanjas Betrachtung der FlashbackSzene aus PROFESSIONE: REPORTER zentral (Coëgnarts/Kravanja: Towards an Embodied Poetics of Cinema). Im Fokus der Analyse verkörperter Bedeutung anhand einer Analyse von ImageSchemata und konzeptuellen Metaphern stand dort ein gegebener Raum und was sich in diesem Raum bewegt: ein Zimmer mit Veranda, durch das sich in diesem Fall eine Kamera bewegt - ein Objekt also, das zwar nicht selbst zu sehen ist, jedoch durch die Verlagerung des Ausschnitts, den die Kamera vom apriorisch gegebenen Raum zeigt, als indirekt repräsentiert gilt.

118 Kappelhoff: Ausdrucksbewegung und Zuschauerempfinden, S. 76.

119 Kappelhoff: Matrix der Gefühle, S. $21 \mathrm{f}$. 
gung ist vielmehr von einer verkörperten Wahrnehmung die Rede. Nicht das Dargestellte steht im Vordergrund, sondern die Idee eines kinematografischen Verhaltens, eines Zur-Welt-Seins - im Sinne „eines performativen, verkörperten Ausdrucks einer Wahrnehmung als Affekt, Sensation und somatischer Empfindung“, ${ }^{120}$ für den, wie Christiane Voss es gefasst hat, der „Zuschauer als Leihkörper“121 und Resonanzkörper fungiert. Es geht darum, audiovisuelle Bilder als Bewegungsbilder zu begreifen: als Bilder, denen Bewegungen, Affekte innewohnen, „die der Zuschauer als strukturierte, gestaltete Zeit seines Wahrnehmungsprozesses verwirklicht““ ${ }^{122}$ Filmische Expressivität wird als die Artikulation audiovisueller Bewegungsgestalten gefasst, als sich entfaltende expressive Qualitäten, die sich in der Zuschauerwahrnehmung als gefühlte Erfahrung realisieren - insofern der sinnlich-körperliche Wahrnehmungsprozess und damit affektive Resonanzen von Zuschauern modelliert werden. Im Verlauf eines Films durchlebt der Zuschauer also eine Komposition von Bewegungsfigurationen, modellieren die Filmbilder in ihrer Zeitlichkeit ein Zuschauergefühl. Mit dem Konzept der Ausdrucksbewegung lassen sich demnach filmische Affektdramaturgien nachzeichnen - Muster von Affektverläufen, die sich jeweils filmspezifisch ausprägen. $^{123}$

Die filmische Ausdrucksbewegung nach Kappelhoff trifft somit den Kern einer situativ-verkörperten Dimension audiovisueller Bilder. Benannt ist mit jenem Begriff eine Sphäre zweier ineinander verflochtener, miteinander ver-

120 In gewisser Weise unterhält „der Film als ein ,Organismus“ ein physisches und affektives Verhältnis zu dem [...], was auf der Leinwand sichtbar wird oder unsichtbar bleibt“. (Morsch: Medienästhetik des Films, S. 307.)

121 Vgl. Christiane Voss: Filmerfahrung und Illusionsbildung. Der Zuschauer als Leihkörper des Kinos. In: ... kraft der Illusion. Hrsg. v. Gertrud Koch und Christiane Voss. München: Wilhelm Fink 2006, S. 71-86; Christiane Voss: Der Leihkörper. Erkenntnis und Ästhetik der Illusion. München: Wilhelm Fink 2013. „[Es ist] der Zuschauerkörper in seiner geistigen und sensorisch-affektiven Resonanz auf das Filmgeschehen [...], der der Leinwand allererst einen dreidimensionalen Körper leiht und somit die zweite Dimension des Filmgeschehens in die dritte Dimension des spürenden Körpers kippt. Der Betrachter wird somit selbst zum temporären ,Leihkörper ' der Leinwand und ist damit seinerseits konstitutiver Bestandteil der filmischen Architektur.“ (Voss: Filmerfahrung und Illusionsbildung, S. 81.) Im Rückgang auf Dewey fasst Voss (ebd., S. 72) das Ästhetische im Allgemeinen wie die filmische Erfahrung im Besonderen daher als „eine intrinsische Verwobenheit von Rezeption und Produktion/Präsentation“.

122 Kappelhoff: Matrix der Gefühle, S. 21. Vgl. auch Deleuze: „Der Film gibt uns kein Bild, das er dann zusätzlich in Bewegung brächte - er gibt uns unmittelbar ein Bewegungsbild.“ (Deleuze: Das Bewegungs-Bild, S. 15.)

123 Psychologisch-empirische Forschungen zu Film und Verkörperung unterstützen die Annahme, dass Zuschauer aufgrund der temporalen Strukturiertheit von Filmen Affektverläufe durchleben (für eine Übersicht hierzu vgl. Bakels: Embodying Audio-Visual Media). 
schränkter und synchronisierter Wahrnehmungsakte: der Wahrnehmungsakt des audiovisuellen Bildes und der seines Zuschauers im Moment der filmischen Kommunikation - ob nun in Form eines Werbefilms, Nachrichtenbeitrags oder Spielfilms. Zeitlichkeit, die in Sobchacks Modell letztlich doch eher implizit bleibt (insofern sie sich vor allem mit der Konstellation der Wahrnehmungsverschränkung befasst), ist damit ins Zentrum gerückt - und verkörperte Audiovision nicht ohne ihre konstitutiv dynamische Verfasstheit als „compositions in and of time“ zu begreifen: ${ }^{124}$

[...] only temporality brings into being the ,tuning' of spectator and film. Therefore embodiment has to be thought of as a matter of permanent shifting, of a dynamic changing between being involved in film and experiencing the own bodily resonances. Embodied audio-vision thus can be grasped as affective intensities: rhythmic mergings, time spans of tension and release. This is the way in which a cinematic movement transforms into the spectator's feeling. ${ }^{125}$

Die analytische Herangehensweise an die Dimension der filmischen Expressivität, der filmischen Ausdrucksbewegung, in der sich die innere Bewegung des audiovisuellen Bildes mit der Empfindungsbewegung des Zuschauers verschränkt, sei nun an der vERTigo-Szene veranschaulicht, deren Handlungsraum ${ }^{126}$ Ernie's Restaurant ist (0:16:09-0:17:44) und deren Anfang bereits oben für Sobchacks Idee einer wahrgenommenen Wahrnehmung illustrierend herangezogen wurde. ${ }^{127}$ Betrachtet wird damit eine gänzlich dialogfreie Szene, der voranging, dass Scottie in Ernie's Restaurant einbestellt worden ist, um Madeleine - jene Frau also, die er beschatten soll, weil sie mutmaßlich Selbstmordgedanken in sich trägt - erstmalig in Augenschein zu nehmen.

Spräche man allein vom Plot, wäre zu dieser Szene nicht viel mehr zu sagen, als dass eben jenes Beschatten seinen Anfang nimmt, das sich in der vorherigen Szene auf Dialogebene angekündigt hat („I want you to follow my wife. [...] We're dining at Ernie's [...]. You can see her there.“): Scottie sitzt an der Restaurant-Bar, um sich Madeleine, ohne dass diese es bemerkt, anzuschauen. Nach einer Weile,

124 Schmitt/Greifenstein: Cinematic Communication and Embodiment, S. 2067.

125 Ebd., S. 2068.

126 Jenes Verständnis von filmischer Bewegung, das in Relation zum Konzept eines apriorisch gegebenen Raumes steht, verbindet sich, so Kappelhoff, immer auch mit der Idee eines Handlungsraums. Denn „diese Welt [stellt sich] den Zuschauern immer schon dar als eine Welt, die auf eine andere, fremde Subjektivität bezogen ist. Das Bild erschließt sich hier als ein sinnhaftes Geschehen“ - als eine „sinnhafte Handlung fiktionaler Figuren“. (Kappelhoff: Ausdrucksbewegung und Zuschauerempfinden, S. 74, 76.)

127 Vgl. zur vorangegangenen verTigo-Analyse Kapitel 8.2 der vorliegenden Arbeit. 
während derer Scottie Madeleine aus einiger Entfernung beobachtet, steht Madeleine von ihrem Tisch auf und verlässt gemeinsam mit ihrem Mann das Restaurant, wobei sie sich Scottie zwischenzeitlich räumlich nähert, sodass dieser den Blick abwenden muss, um nicht als Beobachter von ihr entdeckt zu werden.

Betrachtet man hingegen das dynamische Muster dieser Szene, wird eben das greifbar, was zuvor als Verhaltensdimension des audiovisuellen Bildes umschrieben wurde: eine Komposition von drei Bewegungsfigurationen, durch die sich über die gesamte Szene eine sehr spezifische Erfahrung eines Sehens entfaltet ein Sehen voll aufkeimenden Begehrens, unerwarteter Erfüllung und Verlust zugleich. Es ist ein Sehen von Madeleine, das nicht auf Ebene der gezeigten Figurenhandlung, sondern allein in der raum-zeitlichen Erfahrung des Zuschauers sich realisiert findet, wie sie vom audiovisuellen Bild modelliert wird, wenn in einer spezifischen Erfahrung des In-Kontakt-Kommens ${ }^{128}$ sich ein spezifisches Bild einer „Liebe auf den ersten Blick“ entfaltet. Dies sei zunächst mit Blick auf die Komposition der gesamten Szene erläutert.

Die Szene inszeniert ein Bild des erstmaligen Sehens von Madeleine, ein Bild der Liebe auf den ersten Blick als dynamisches Muster eines getragenen, sanften Annäherns (erste Ausdrucksbewegung; gestaltet durch Kamerabewegung, Bildkomposition und Sound), welches sich in ein Nähern sich steigernder Intensität transformiert (zweite Ausdrucksbewegung; gestaltet durch Bildkomposition, Montage, Figurenbewegung und Sound) und seinen Höhepunkt und seine Auflösung im Erleben eines sich ergießenden, flüssigen Miteinander-Verschmelzens und sanften Voneinander-Lösens findet (dritte Ausdrucksbewegung; gestaltet durch Schauspiel, Montage und Sound). Wesentlich getragen wird die Gesamtkomposition der Szene durch ihre musikalische Komposition. In einer spätromantisch alterierten, d. h. nicht eindeutig Moll oder Dur zuordenbaren Harmonik sowie einer chromatisierten, sich also viel in Halbtonschritten bewegenden Melodik, die Anleihen bei Richard Wagners „Liebestod“ aus Tristan und Isolde nimmt, erklingen SordinoStreicher (d. h. mit Dämpfer spielend) und einmalig eine Harfe. Die Komposition greift den rhythmischen Gestus eines Walzers auf, dessen Dreiertakt allerdings durch ein starkes Rubato (durch zeitliche Dehnungen und Stauchungen also) sowie durch melodische Bindungen über den Taktschwerpunkt hinweg verunklart ist - doch zugleich sind die musikalischen Phrasen klar zu erfassen. ${ }^{129}$ Und so entfaltet sich diese Szene in einem Tanz mit immer wieder neu anhebenden Melodiebögen: anfänglich getragen und zurückhaltend im tieferen Ton-

128 Allein von der Handlungslogik aus betrachtet, kommt es in dieser Szene weder zu einem direkten Blickkontakt noch zu einer Berührung zwischen Madeleine und Scottie.

129 Ich danke Philip Peter und Marcella Feiten für ein musikanalytisches Gespräch zu dieser Szene. 


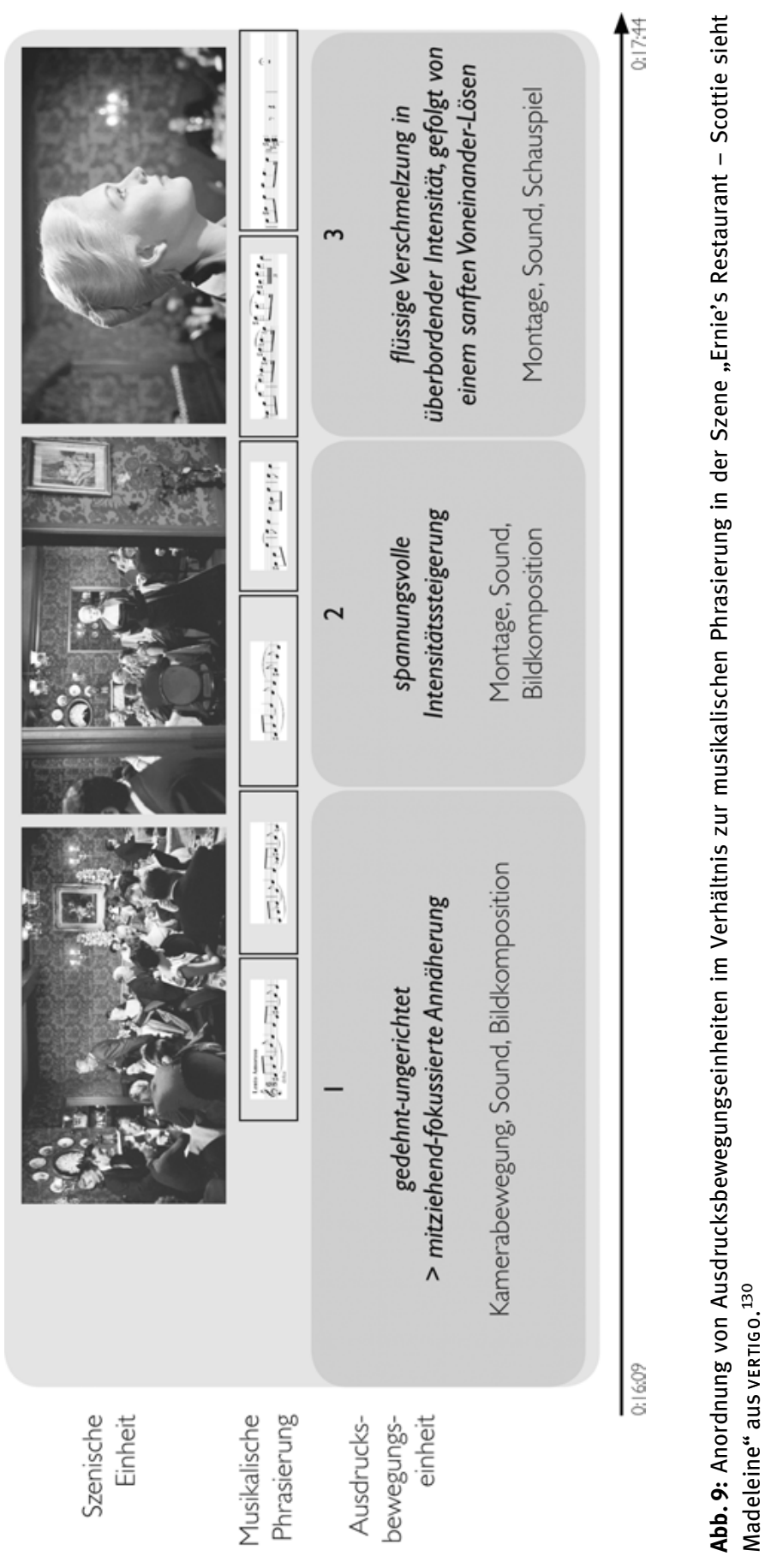


bereich (in der ersten Ausdrucksbewegung), dann allmählich ansteigend (in der zweiten Ausdrucksbewegung), bis sich die Komposition schließlich mit überbordender Intensität in einem Lauf von hoch oben hinab schmelzend ergießt und langsam ausklingt (in der dritten Ausdrucksbewegung). Für die audiovisuelle Komposition der Szene ist das Verwobensein von Bild und Ton zentral ${ }^{131}$ - dies zeigt sich nicht zuletzt auch daran, dass der Wechsel von einer Ausdrucksbewegung zur nächsten nicht nur durch Veränderung in der visuellen Inszenierung, sondern jeweils auch durch einen neu ansetzenden Melodiebogen gestaltet ist (vgl. Abb. 9)^. Wie sich die drei Ausdrucksbewegungen figurieren, sei nun genauer nachgezeichnet.

Erste Ausdrucksbewegung. Durch das Zusammenspiel von Kamerabewegung, Sound/Musik und Bildkomposition transformiert sich eine gedehnte und ungerichtete in eine mitziehende, sanft soghafte Bewegungsqualität einer fokussierten Annäherung.

Am Anfang steht Scotties ins Off schauende Gesicht, während er an der Bar sitzt. ${ }^{132}$ Doch in einer lang andauernden Totalen entfernt sich die Kamera sogleich rückwärts von Scottie und seinem Blick, gleitet dabei mit einer fließenden, den bis auf den letzten Platz besetzten Speiseraum überblickenden, gedehnten Bewegung nach links, bis die Kamera sanft, für den Bruchteil eines Augenaufschlags nur, innehält. Währenddessen sind leises Geschirrklappern und das undifferenzierte Stimmengewirr der Restaurantgäste zu hören. Und so undifferenziert die akustische Ebene ist, so undifferenziert ist auch der visuelle Eindruck bis hierhin. Mit seinen Stofftapeten, Blumengestecken, Lampen und dicht an dicht sitzenden Gästen ergießt sich das Restaurant in einem Farbenmeer von satten Rot-, Weiß-, Schwarz- und Grautönen. Jene gedehnte, ungerichtete Bewegung hat sich in eine mitziehende, sanft soghafte Bewegung einer Fokussierung transformiert, wenn mit dem Einsetzen einer sanften, melancholischen Streichermusik die vorherige ungerichtete Soundkulisse abgelöst wird und zugleich die Kamera zu einer erneuten langsamen und kontinuierlichen, nun nach vorne gerichteten Bewegung

130 Die Notation der ersten Violine aus Herrmanns Filmmusikkomposition dieser Szene ist entnommen aus Claudia Bullerjahn: Von Hollywoods Studiosystem zur Vermarktung populärer Kinohits. In: Musik und Ökonomie. Finanzieren und Vermarkten von und mit Hilfe von Musik Musikästhetisches und musikpädagogisches Haushalten. Hrsg. v. Claudia Bullerjahn und Wolfgang Löffler. Hildesheim: Olms 2009, S. 299-350, hier S. 319. Die drei Stills stehen beispielhaft für die Montagesequenz der jeweiligen Ausdrucksbewegungen.

131 Beispielhaft zeigt die gesamte Szene die ästhetische „explosive effectiveness“ eines „cinemusical amalgam“, mit dem etwa Schneller Hitchcocks Filme beschreibt, bei denen Herrmann die Filmmusik komponierte (Tom Schneller: Death and Love. Bernard Herrmann's Score for Vertigo. In: Cuadernos de musica, artes visuales y artes escenicas 1.2 (2005), S. 189-200 hier S. 199).

132 Dem voran geht noch ein establishing shot, der das Restaurant mit Namen von außen zeigt. 
anhebt. In gemäßigtem Tempo und in Legato-Strichen erklingt zugleich eine Melodie, mit nach oben und wieder hinuntersteigenden Tonfolgen. Der Visualisierung einer geschwungenen Tonfolgen-Linie der ersten musikalischen Phrase gleichend wird nun zunächst das Bildfeld horizontal von einem Kellner und zwei ihm folgenden Gästen durchquert, bis der Blick wieder freigegeben ist, und eine Frau schließlich die Mitte des Bildfeldes einnimmt. Das Bildfeld entleert sich im Zuge der fortdauernden Annäherung, bis mit dem Ende der zweiten musikalischen Phrase nur noch einige wenige andere Gäste im Umraum der zentrierten Frau drapiert sind: Madeleines Gesicht ist der Kamera abgewandt, ihr tiefgrünes Kleid mit dem tiefen Rückendekolleté hebt sich klar aus dem bisherigen Farbraum der Rot-, Weiß- und Schwarztöne ab. (Abb. 10)^
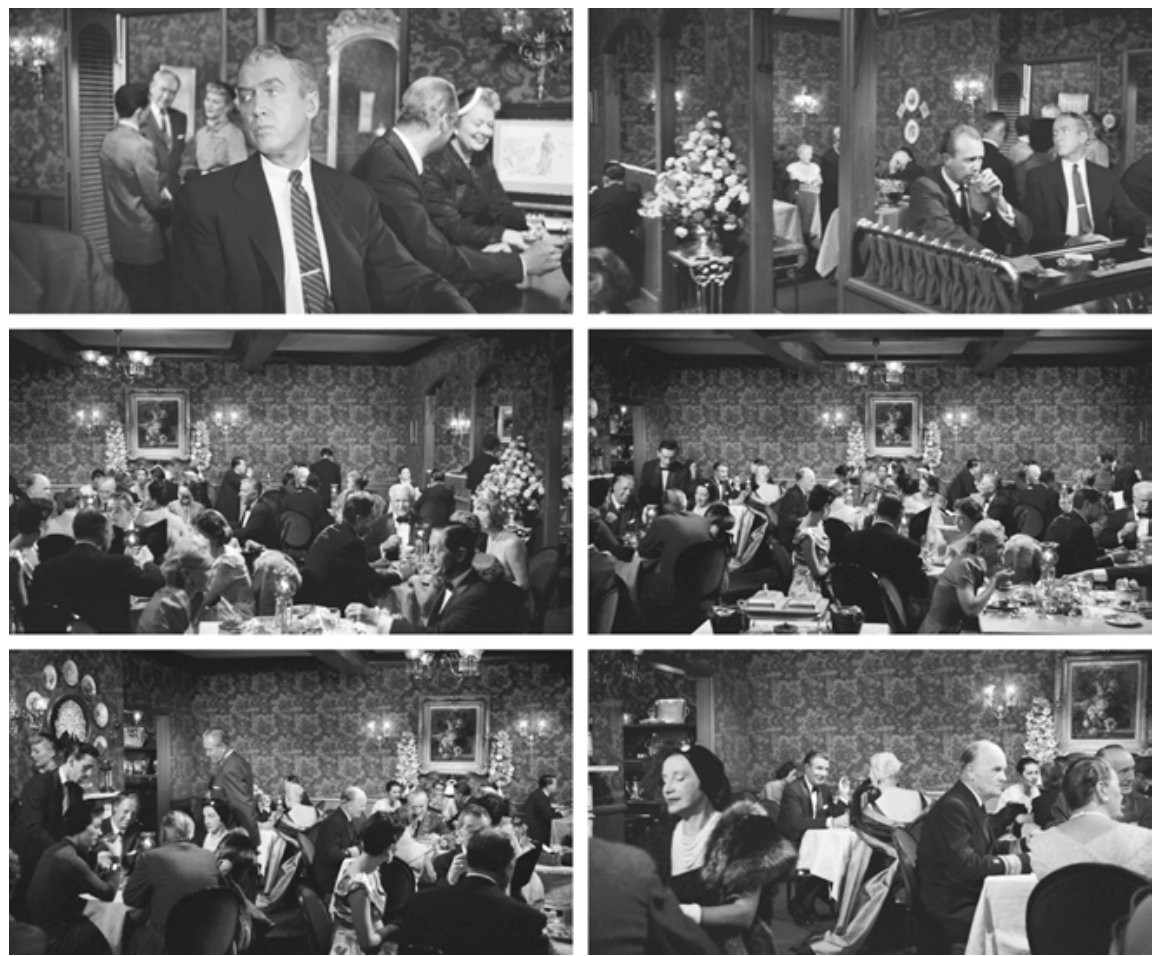

Abb. 10: Erste Ausdrucksbewegung - Durch das Zusammenspiel von Kamerabewegung, Sound/ Musik und Bildkomposition transformiert sich in einer ersten Ausdrucksbewegung eine gedehnte und ungerichtete in eine mitziehende, sanft soghafte Bewegungsqualität einer fokussierten Annäherung (vertigo, Szene: „Ernie's Restaurant - Scottie sieht Madeleine“, $0: 16: 16-0: 16: 54)$. ( $\rightarrow$ Abb. $10 \star$, Farbbogen) 

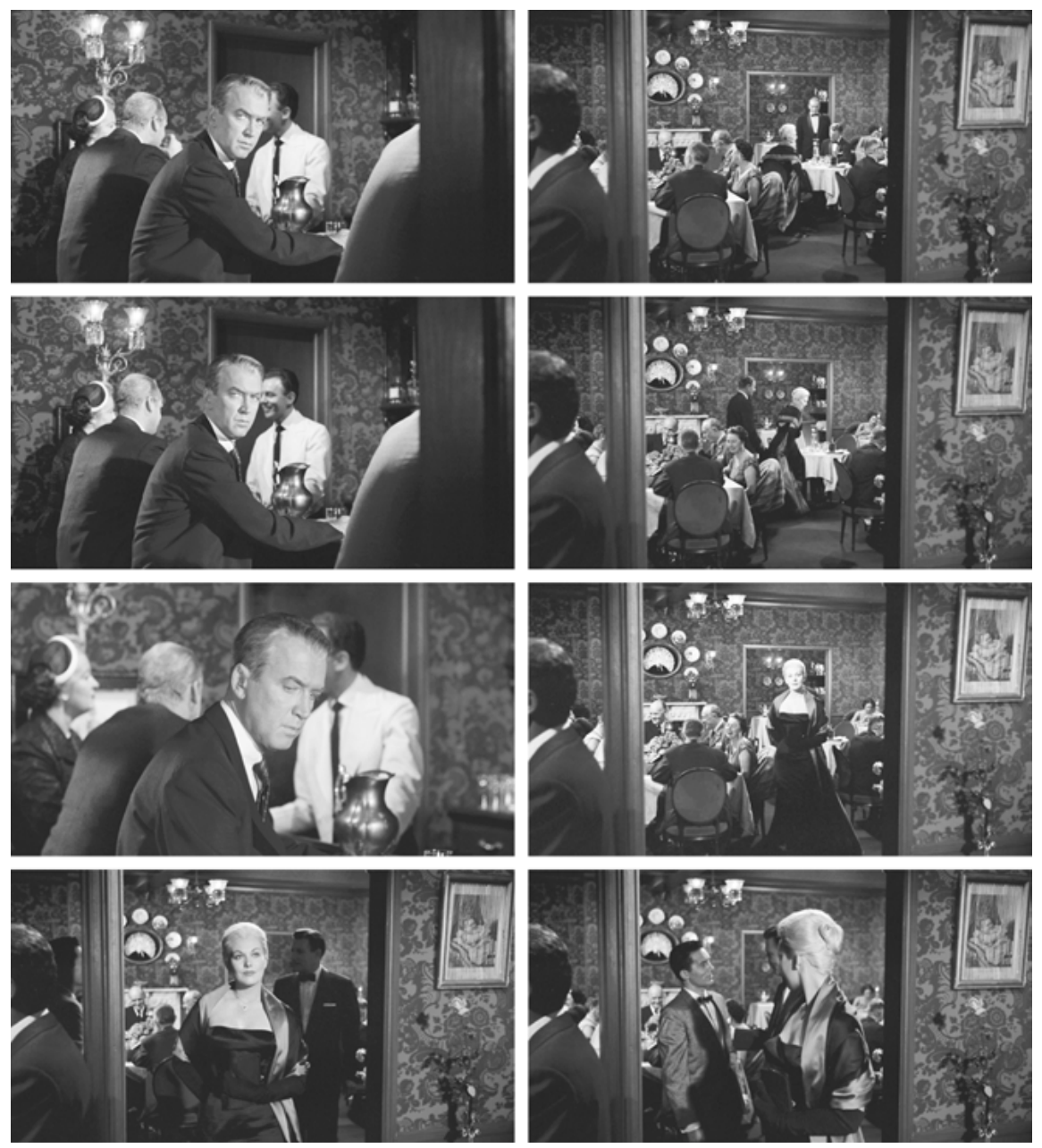

Abb. 11: Zweite Ausdrucksbewegung - Durch das Zusammenspiel von Montage, Bildkomposition, Figurenchoreografie und Musik entfaltet sich in der zweiten Ausdrucksbewegung erneut eine Annäherung, deren Bewegungsqualität nun als eine sich steigernde, spannungsvolle Intensität zu beschreiben ist: durch ein Verwobensein von drängender Geradlinigkeit und verzögernden Drehungen (VERTIGo, Szene: „Ernie’s Restaurant Scottie sieht Madeleine“, 0:16:54-0:17:16). ( $\rightarrow$ Abb. 11*, Farbbogen) 

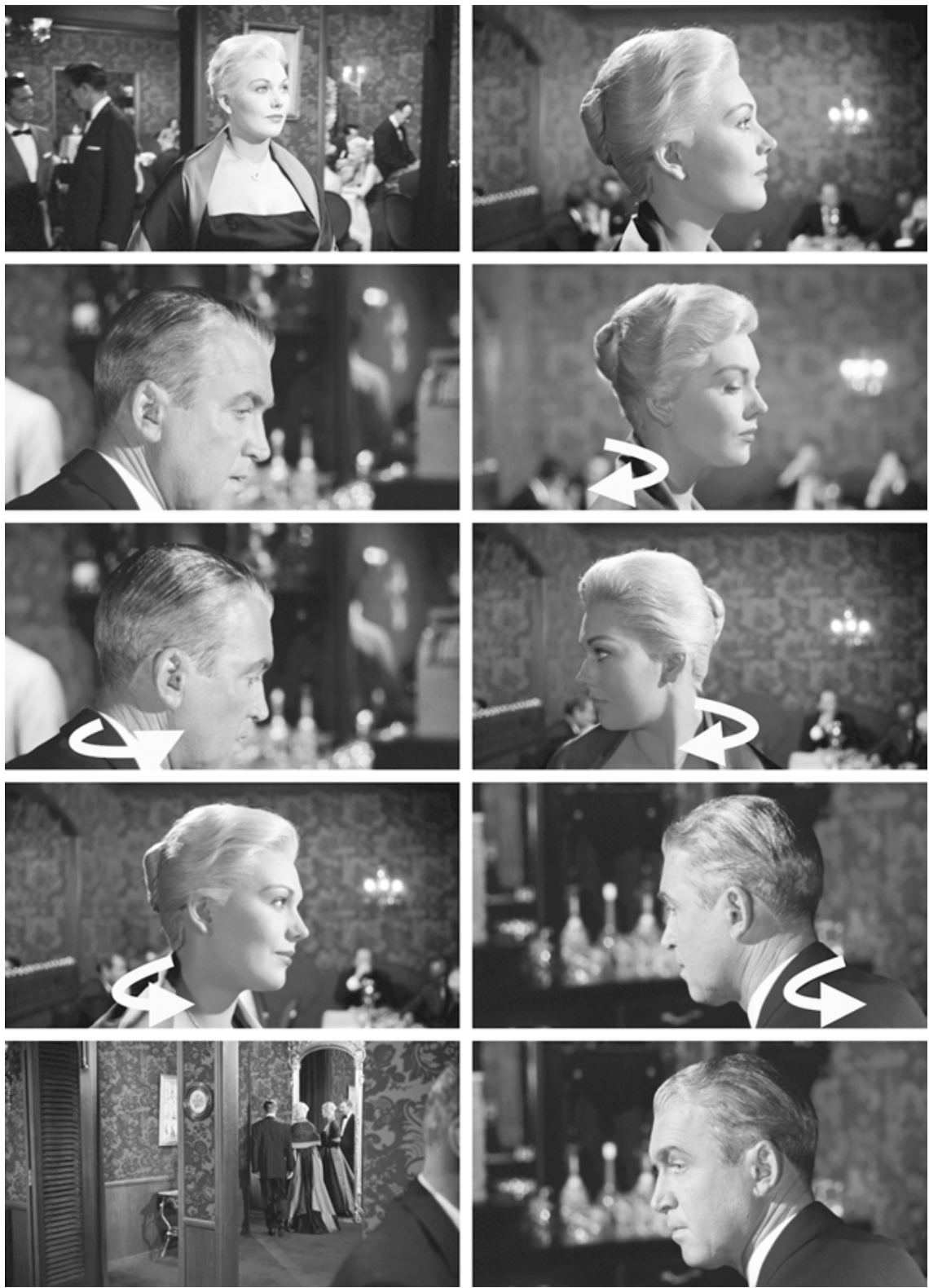

Abb. 12: Dritte Ausdrucksbewegung - Durch das Zusammenspiel insbesondere von Montage, Figurenbewegung und Musik wird das Erleben eines flüssigen Miteinander-Verschmelzens in einer sich ergießenden Drehung und eines sanften Voneinander-Lösens evoziert; Pfeile = Drehbewegungen des Schauspiels. (vertigo, Szene: „Ernie's Restaurant - Scottie sieht Madeleine“, 0:17:16-0:17:44.) ( $\rightarrow$ Abb. 12*, Farbbogen) 
Zweite Ausdrucksbewegung. Durch das Zusammenspiel von Montage, Bildkomposition, Figurenchoreografie und Musik entfaltet sich erneut eine Annäherung, deren Bewegungsqualität nun als eine sich steigernde, spannungsvolle Intensität zu beschreiben ist: durch ein Verwobensein von drängender Geradlinigkeit und verzögernden Drehungen.

Mit dem Anheben zur dritten musikalischen Phrase ist die Kamera zu Scotties Blick zurückgekehrt, und erneut wird sich im Folgenden ein Sehen von Madeleine entfalten. Doch hatte sich zuvor der Raum für das Sehen in einer fließenden Bewegung in die Fläche geöffnet, erfolgt das Sehen nun in Form einer frontalen Staffelung und Schichtung in die Tiefe. Eine Schuss-Gegenschuss-Montage wechselt zwischen Ansichten von Scottie und Madeleine hin und her. Nach und nach, über eine Halbnahe bis hin zu einer Großaufnahme, rückt die Kamera dabei näher an den weiterhin an der Bar sitzenden und alsbald den Blick abwendenden Scottie heran. Und auch in den Einstellungen, die Madeleine zeigen - obgleich die Kamera hier statisch bleibt - erfolgt gewissermaßen eine stete Rekadrierung, von der Totalen hin zur Halbnahen. Evoziert ist dies durch den Gang Madeleines frontal auf die Kamera zu, wenn sie sich vom Tisch erhoben hat; ein Gang verwoben mit einer zentralperspektivischen Bildkomposition: Eine Surcadrage aus sich staffelnden Rahmen von Durchgängen lässt Madeleine aus der Tiefe des Raumes hervortreten. Zugleich jedoch wird die in der Bildkomposition und Montage gründende drängende Geradlinigkeit der Annäherung Madeleines an Scottie durch ein unablässiges Spiel filigraner Drehungen stetig verzögert. Es sind dies sanfte Drehungen, die sich durch das feingliedrige Zusammenspiel und Verschmelzen von Figurenbewegung, musikalischer Bewegung und den Wechsel von Einstellungen figurieren. Das Bild ist musikalisiert, der Ton choreografiert: So, wie die Tonfolgen sich in Bögen bewegen, so dreht sich Scotties Kopf, wenn er den Blick von der sich nähernden Madeleine abwendet; und so figuriert sich auch mit dem Ausklang der vierten musikalischen Bogenphrase eine runde Konstellation durch die Figurenbewegung: Madeleine, ihr Mann und einer der Kellner wenden sich einander zu, fügen sich für einen Moment zu einer Art Kreis. Dabei wendet Madeleine ihr der Kamera zuvor zugewandtes Gesicht wieder ab - ihr Anblick verzögert sich ein letztes Mal. (Abb. 11)*

Dritte Ausdrucksbewegung. Durch das Zusammenspiel insbesondere von Montage, Figurenbewegung und Musik wird das Erleben eines flüssigen Miteinander-Verschmelzens in einer sich ergießenden Drehung und eines sanften Voneinander-Lösens evoziert.

Madeleine wendet sich nun der Kamera wieder zu und nähert sich ihr weiter, bis sie innehält und das Bildfeld ihren Kopf zentriert und in seitlicher Großaufnahme zeigt. Im Zuge dessen verändert sich auch die Schärfeneinstellung, denn alle bisherige Tiefenschärfe entweicht aus dem Bild: Der Fokus liegt nun allein 
auf diesem hell erstrahlenden Gesicht vor rotem Grund. Zugleich hat die nächste musikalische Phrase angehoben, immer höher und höher hinauf reichen die Tonbögen. Noch im letzten Moment dieses bogenhaften Hinaufsteigens wechselt die Einstellung: Scotties Gesicht ist zu sehen, gleichfalls in einer seitlichen Großaufnahme ohne Tiefenschärfe - auch sein Gesicht ist, wie ihres, fast ohne mimische Regung. Und nun ergießen sich die Geigen zusammen mit einer Harfe schmelzend und mit überbordender Intensität in einem Lauf von hoch oben hinab - und damit setzt sich auch der Wechsel der Großaufnahmen von Madeleine und von Scottie, deren Mimik auf den Augenaufschlag reduziert ist, in rascher Folge fort: Verharrten die Köpfe soeben noch in der Seitansicht, haben sie sich jetzt $\mathrm{zu}$ drehen und wenden begonnen, und durch die gleichförmige Geschwindigkeit verschmelzen die Bewegungen von Madeleine und Scottie in der Montage und im Zusammenspiel mit den sich ergießenden Geigen in einer einzigen, gemeinsamen, flüssigen Drehung - bis sich mit dem Einsatz des letzten Melodiebogens die Gesichter wieder voneinander zu lösen beginnen: Madeleine wendet ihren Kopf in die entgegengesetzte Richtung und verlässt das Bildfeld, im Nachklang dreht Scottie noch einmal seinen Kopf, die Tiefenschärfe kehrt zurück, der Bann der Großaufnahme ist aufgehoben. In einer Halbtotalen sehen wir, wie Madeleine am Arm ihres Mannes in Rückansicht das Restaurant verlässt, bis schließlich die Kamera noch ein letztes Mal auf Scotties schauendem Gesicht verweilt und die Musik mit dem tiefen Klang eines Cellos, das noch ein letztes Mal den Melodiebogen der Geigen erklingen lässt, zur Ruhe kommt. (Abb. 12)^

Auf einer methodischen Metaebene betrachtet, ist das zentrale Instrument einer solchen Analyse filmischer Expressivität, wie zu sehen war, eine qualifizierende Segmentierung. ${ }^{133}$ So werden audiovisuelle Datensätze auf einer Makroebene zunächst in szenische Einheiten segmentiert. Und innerhalb dieser szenischen Einheiten wiederum wird eine mikroanalytische Segmentierung in

133 Methodische Bezugsfolie zur Untersuchung filmischer Expressivität ist eMaex - electronically based media analysis for expressive movement images. Vgl. Kappelhoff/Bakels: Das Zuschauergefühl; Hermann Kappelhoff: eMAEX - Eine systematisierte Methode zur Untersuchung filmischer Ausdrucksqualitäten. In: Empirische Medienästhetik 2010-2014 (https://www.empirische-medienaesthetik.fu-berlin.de/emaex-system/emaex_kurzversion/index.html, zuletzt eingesehen: 22.11.2018). Dies ist eine operationalisierte Vorgehensweise zur qualitativen Filmanalyse, die im Rahmen eines Forschungsprojekts zur Affektmobilisierung und medialen Kriegsinszenierung unter der Leitung von Hermann Kappelhoff im Rahmen des Exzellenzcluster „Languages of Emotion“ (Freien Universität Berlin) maßgeblich für ein digitales Umfeld multimedialen Publizierens entwickelt wurde und im Kontext der vorliegenden Arbeit ihre analoge Aneignung findet. Vgl. zur Methodik auch Hermann Kappelhoff/Jan-Hendrik Bakels/Sarah Greifenstein: Die Poiesis des Filmesehens. Methoden der Analyse audiovisueller Bilder. Berlin/Boston: Walter de Gruyter (in Vorbereitung). 
Einheiten von Ausdrucksbewegungen vorgenommen. Auf diese Weise werden Szenen als Kompositionen aus mehreren gestalthaften audiovisuellen Bewegungsfigurationen, die jeweils in spezifischer Weise artikuliert werden, fassbar (es ist auch möglich, dass Szenen aus einer einzelnen Ausdrucksbewegung bestehen). In einer Ausdrucksbewegungseinheit verbinden sich dabei Dynamiken offensichtlicher Bewegung (wie etwa des Schauspiels oder der Kamera) mit komplexeren Formen audiovisueller Transformation. Das heißt, dass das audiovisuelle Bild auf zeitliche Figurationen hin untersucht wird, wie sie inszenatorisch durch formale Gestaltungsmittel evoziert werden. Zentrale Gestaltungsmittel, mit denen man sich der Vieldimensionalität audiovisueller Bilder, den multiplen Modalitäten filmischen Ausdrucks analytisch nähern kann, sind:

- Kamera (Einstellungsgröße, Kamerabewegung und -perspektive, Einstellungsmontage und Montagerhythmus) ${ }^{134}$

- Sound (Musik, Geräusche, stimmliche Artikulationen)

- Schauspiel (Gestik, Mimik, Körperbewegungen)

- Figurenkonstellation (Choreografie/Konstellation von Figuren und Objekten im Sinne eines engen Verständnisses von Mise-en-Scène)

- Bildkomposition (Kontrast- und Farbverteilung, Lichtvaleurs, visuelle Muster und Bildaufteilung, Dynamik im Bild)

Betrachtet man filmische Gestaltungsmittel hinsichtlich der Artikulation expressiver Bewegung, dann werden analytisch durchaus differenzierbare Aspekte einer audiovisuellen Orchestrierung gerade nicht als separate Eindrücke gefasst. In den Blick kommen vielmehr expressive Qualitäten, die aus einem sich immer wieder verändernden, dabei jedoch gestalthaften Zusammenspiel von Inszenierungsmitteln hervorgehen. ${ }^{135}$ Die unterschiedlichen expressiven Modalitäten treten dabei mal mehr, mal weniger dominant in der filmischen Ausdrucksgestaltung in Erscheinung.

134 In der Rolle der Einstellungsmontage liegt ein signifikanter Unterschied des Konzepts der filmischen Ausdrucksbewegung nach Kappelhoff und Bellours Auseinandersetzung mit den Stern'schen Vitalitätsaffekten. Bellour erhebt die Einstellung zur zentralen analytischen Bezugsgröße (Raymond Bellour: Daniel Stern und die Einstellung. In: Synästhesie-Effekte. Zur Intermodalität der ästhetischen Wahrnehmung. Hrsg. v. Robin Curtis, Marc Glöde und Gertrud Koch. München: Fink 2010, S. 35-49). Das filmanalytische Konzept der Ausdrucksbewegung hingegen fasst Montage als eine substantielle Artikulationsform filmischer Expressivität auf.

135 Ein solches Ineinandergreifen von Bewegungen innerhalb einer Bewegungsgestalt führt auch Plessner am Beispiel des Gehens aus: „Zu jedem einfachen Schritt, der in einer einfachen Gestalt erfolgt, gehören eine ganze Anzahl ineinandergreifender Körperbewegungen, die weder für den Betrachter noch für den Gehenden anschaulich gegeben sind.“ (Plessner: Die Deutung des mimischen Ausdrucks, S. 77 f.) 
Mit der filmischen Expressivität artikuliert Film ein Wahrnehmen als Verhalten, als ein Zur- und In-der-Welt-Sein - welches der Zuschauer in seiner Wahrnehmung allererst noch reflexiv-verkörpernd verwirklicht, als Wahrnehmung eines anderen. Zuschauen heißt, in die Schicht filmischen Verhaltens eingelassen, mit ihr synchronisiert zu sein: Die gestische Dimension des Films, die Bewegungsbilder organisieren die Wahrnehmung ästhetisch, raum-zeitlich. Film und Zuschauer befinden sich in einem Sinnlichkeitskontinuum.

Das darstellende Vermögen filmischer Bilder ist mit dieser als und durch Bewegung zur Anschauung gebrachten Wahrnehmungsweise immer schon zusammenzudenken. Und in der filmischen Expressivität verortet sich noch die Voraussetzung und Grundlage für Prozesse filmischer Bedeutungskonstitution, die eine Dimension des Medienumgangs, des Mediengebrauchs, der cinematic communication ist.

\section{Rückkopplung II: Ähnlichkeiten filmischer und menschlicher Expressivität}

Doch bevor im nächsten Abschnitt das Semioseverständnis filmischer Expressivität erläutert wird, soll sich hier kurz auf das Alltagsgespräch als Form eines Diskursereignisses rückbezogen werden. Denn an obiger Beispielanalyse filmischer Expressivität lassen sich Ähnlichkeiten zu körperlicher Expressivität in der Alltagskommunikation aufzeigen. Anhand von zwei Aspekten sei der oben ausgelegte argumentative Faden wieder aufgegriffen, inwiefern es phänomenal begründet ist, eine Auseinandersetzung mit kommunikativen Face-to-Face-Interaktionen in Überlegungen zur Interaktion zwischen audiovisuellem Bild und Zuschauer miteinzubeziehen - freilich ohne dies gänzlich miteinander gleichsetzen zu wollen.

Adam Kendon, dessen Gestenforschungen zu der These, dass „speech and movement appear together as manifestations of the same process of utterance“, ${ }^{136}$ für die Linguistik wegweisend waren, hat für die Analyse von Gesten die „gesture unit“ einführt. Die Wahrnehmungsgestalt der Geste wird hier als eine Einheit beschrieben, die sich aus Phasen fügt. Jana Bressem und Silva Ladewig fassen dies wie folgt zusammen:

136 Adam Kendon: Gesticulation and Speech. Two Aspects of the Process of Utterance. In: The Relationship of Verbal and Nonverbal Communication and Language. Hrsg. v. Mary R. Key. The Hague [u. a.]: De Gruyter Mouton 1980, S. 207-227, hier S. 208. Vgl. auch Adam Kendon: Some Relationships Between Body Motion and Speech. In: Studies in Dyadic Communication. Hrsg. v. Aron W. Siegman und Benjamin Pope. Elmsford: Pergamon 1972, S.177-210; Adam Kendon: Gesture. Visible Action as Utterance. Cambridge: Cambridge University Press 2004. 
When people gesture, they move their hands and arms in a particular succession. Starting from a relaxed position, such as on their lap or on a table, they move them to a place in front of their body, where they may perform further movements, and then back to a relaxed position again. These successions, first defined by Kendon (1980), are referred to as „gesture phases" and describe the different movement phases observable in the execution of gestures. The meaningful part of the gesture - the part people rely on in their interpretation of a gesture - is the stroke. In order to perform a stroke, the hands need to prepare for its execution during the phase referred to as preparation. The stroke may be followed by a retraction, a phase in which the hands relax and move back into a rest position. ${ }^{137}$

Rein formal wird in der Gestenforschung der Stroke auch als die Phase beschrieben, die am klarsten artikuliert ist. ${ }^{138}$ Als eine ebensolche Phasenfolge hat auch Müller beispielsweise, wie oben wiedergegeben, ${ }^{139}$ die funkenschlagende RingGeste beschrieben, mit der eine Frau sich und ihrer Gesprächspartnerin das Erleben des ersten Verliebens verkörpernd vergegenwärtigt. Bei der oben analysierten VERTIGo-Szene zeigt sich eine dreiteilige Phasensukzession paradigmatisch an der dritten Ausdrucksbewegung, dem Höhepunkt des in dieser Szene sich entfaltenden Szenarios eines Verliebens. So ist die audiovisuelle Entstehung der Großaufnahme eine Phase des vorbereitenden Auftakts, die der zentralen Hauptphase vorangeht: der sich ergießenden Drehbewegung, zu der die Großaufnahmen von Madeleine und Scottie verschmelzen - bis schließlich mit dem Auflösen der Großaufnahme die Phase des Ausklingens, des Zur-Ruhe-Kommens eintritt.

Mit Blick auf audiovisuelle Bilder lässt sich also sagen, dass die filmische Ausdrucksbewegung als eine Gesteneinheit betrachtet werden kann. Ebenso denkbar ist aber auch, die Szene, die ja, wie bei vertigo beispielhaft gesehen, eine Komposition von mehreren Ausdrucksbewegungen sein kann, als eine aus mehreren Gestenphrasen sich fügende Gesteneinheit aufzufassen. Diese Überlegung legt eine weitere Beobachtung Kendons von Handgestenphasen nahe:

These gesture phases build higher-level units, namely: 1) the [...] gesture phrase, which is composed of a preparation and stroke and 2) the gesture unit, which is „demarcated as extending from the moment $\mathrm{p}$ begins the excursion of the limb to the moment when the limb is in rest again“" (Kendon 1980: 212) and may include one more gesture phrases. ${ }^{140}$

137 Jana Bressem/Silva H. Ladewig: Rethinking Gesture Phases. Articulatory Features of Gestural Movement? In: Semiotica 184.1 (2011), S. 53-91, doi: 10.1515/semi.2011.022, hier S. 55, Herv. CS. 138 Cornelia Müller: Wie Gesten bedeuten. Eine kognitiv-linguistische und sequenzanalytische Perspektive. In: Sprache und Literatur 41.1 (2010), S. 37-68, hier S. 48.

139 Vgl. Kapitel 7.2 der vorliegenden Arbeit.

140 Bressem/Ladewig: Rethinking Gesture Phases, S. 55. 
Bezogen auf audiovisuelle Bilder, lässt sich mit dieser Betrachtung hervorheben, dass im theoretischen Kontext filmischer Expressivität die Rede von szenischen Einheiten in Filmen nicht zuvorderst auf der Ebene narrativer Handlungseinheiten operiert (etwa das Beobachten Scotties von Madeleine in Ernie's Restaurant). Vielmehr geht es um qua formaler Beschreibung rekonstruierbare Kompositionen von Bewegungsmustern, die sich durch eine gestalthafte Ausdrucksebene im Wahrnehmungserleben realisieren. Zugleich unterstreicht dies noch einmal, wie Gestaltphänomene ineinandergefügt sind: ,Film‘ meint ein dynamisches Ganzes, das sich beschreiben lässt als eine Komposition szenischer Ganzheiten, die sich wiederum aus Ganzheiten filmischer Ausdrucksbewegungen fügen, welche in sich selbst noch Gestalten tragen.

Der zweite Aspekt, der die phänomenale Nähe filmischer und menschlicher Expressivität reflektiert, knüpft an diese Ineinanderfügung expressiver Gestaltphänomene an und fokussiert die audiovisuelle Vielschichtigkeit, die sowohl einen Film als auch ein Gespräch charakterisiert. So zeigt sich die verkörperte und interaffektive Dimension, wie sie an der Geste beschrieben werden kann, in Faceto-Face-Gesprächen auch über die einzelne Handgeste hinaus. Dies gilt sowohl hinsichtlich des körperlichen Gesamtausdrucks eines Gesprächsteilnehmers wie auch für die Interaktion aller Teilnehmer (neben Handgesten etwa artikuliert über Positionierungen und Haltungen der Körper zueinander, durch stimmliche wie mimische Bewegungen und Interventionen, durch Blicke und Sprecherwechsel). Letzteres meint entsprechend Ausdrucksbewegungseinheiten, die eine Vielzahl der von Kendon anvisierten manuellen gesture units umfassen und die aus dem Interaktionsfluss von Kommunikationsteilnehmern hervorgehen - wie filmische Ausdrucksbewegungseinheiten können solch interaktive Ausdrucksbewegungseinheiten sich über mehrere Minuten hinweg entfalten. Im menschlichen Verhalten, das eine Gesprächssituation ausgestaltet, entfalten sich so Rhythmen und Intensitäten und realisiert sich damit ein intersubjektiv evoziertes und geteiltes Erleben von Interaffektivität. ${ }^{141}$

\section{Filmische Expressivität und der Prozess der Semiose}

Und auch die gestische Dimension audiovisueller Bilder, das filmische Verhalten ist eben immer schon relational, intersubjektiv, interaffektiv zu denken - gestal-

141 Vgl. ausführlich zur Geste als interaktiver Ausdrucksbewegung und zur Interaffektivität in der Face-to-Face-Kommunikation Horst/Boll/Schmitt/Müller: Gesture as Interactive Expressive Movement sowie Müller/Kappelhoff: Cinematic Metaphor, S. 146-154. 
ten doch die audiovisuellen Bewegungsfigurationen und raumzeitlichen Rhythmisierungen $^{142}$ je ganz konkret und spezifisch die „Zeit des ästhetischen Wahrnehmungsprozesses“. ${ }^{143}$ Mit Kappelhoff lässt sich resümierend festhalten:

Das filmische Bild wird per se als ein Bewegungsbild verstanden, das, intentional gerichtet, eine affektive Haltung zur Welt artikuliert und zugleich von Zuschauern als ein Wahrnehmungserleben erfasst wird, das als Wahrnehmung eines anderen Ichs erscheint. Fragt man nach dem Gefühl des Filme-Sehens, dann betrifft das zuallererst die zeitliche Form des in sich geteilten Wahrnehmens. [...] Das Band, welches Leinwandbild und Zuschauerkörper verbindet, ist weder das Sujet, noch die Handlung, sondern das Vermögen, andere Körper zu affizieren und von anderen Körpern affiziert zu werden. Um die interaffektive Struktur zu begreifen, in der technische und menschliche, künstliche und organische Körper miteinander verschränkt sind, gilt es, sich der Materie zu vergewissern, in der das eine wie das andere gegründet ist; und das ist [...] die Bewegung selbst. ${ }^{144}$

Sagen lässt sich dies in jedem Fall „für alle kinematografischen Erscheinungsweisen audiovisueller Bilder“"145 - und in der Tat entfaltet sich wohl, wie es die Medien- und Kommunikationswissenschaftlerin Angela Keppler formuliert, im Kino das „musikalische Potential des Filmbildes mit höchster Wirkung““. ${ }^{146}$ Doch auch beim Fernsehen etwa haben wir es mit „filmbildlichen Präsentationen“147 zu tun, auch dort entfaltet sich ,ein Klangbildgeschehen [...], das der Wahrnehmung einen virtuellen Bewegungsraum eröffnet“"148 - ein Raum, „der uns [...] in Bewegungen des Sehens, [...] des Hörens und mit ihnen in eine komplexe Bewegung des Verstehens versetzt“. ${ }^{149}$ Damit sei keinesfalls die Relevanz dessen, wie

142 Vgl. ausführlich zum audiovisuellen Rhythmus als einem filmisch-raumzeitlichen Phänomen Bakels: Audiovisuelle Rhythmen.

143 Kappelhoff: Matrix der Gefühle, S. 153, Herv. CS.

144 Kappelhoff: Genre und Gemeinsinn, S. 121.

145 Ebd.

146 Angela Keppler: Mediale Gegenwart. Eine Theorie des Fernsehens am Beispiel der Darstellung von Gewalt. Frankfurt a. M.: Suhrkamp 2006, hier S. 67.

147 Ebd., S. 51.

148 Ebd., S. 68f.

149 Ebd., S. 73. Eine solche Argumentation, mit der sich an Kepplers Theorie des Fernsehens anschließen lässt, zielt zunächst einmal darauf, dass auch das Fernsehen Bewegungsbilder artikuliert. Keppler zufolge sind etwa nicht nur „Dokumentarfilme, Nachrichtenfilme, Fernsehspiel, Spielfilme“, sondern auch „Talkshows, Sportübertragungen, Quizsendungen [...], was ihr Material und ihre Erscheinung betrifft, filmische Inszenierungen“: „Die Ästhetik des Fernsehens“, so Keppler, „ist insgesamt eine filmische“ (ebd., S. 51). Cavell hingegen unterscheidet die „materielle Basis“, die „ästhetische Tatsache“ des Fernsehens (,Strom simultaner Ereignisrezeptionen“) strikt von der des Films („Abfolge automatischer Weltprojektionen“) (Stanley Cavell: Die Tatsache des Fernsehens [1982]. In: Grundlagentexte zur Fernsehwissenschaft. Theorie - 
audiovisuelle Bilder von medialen Dispositiven und Gebrauchskontexten in Szene gesetzt werden, grundsätzlich für die Frage nach einem Wahrnehmen, Fühlen und Verstehen audiovisueller Bilder verneint. (Und auch geht es nicht darum, Nachrichten und Ähnliches zur Kunst zu erklären oder sie in ihrer Komplexität mit Spielfilmen gleichsetzen zu wollen.) Doch sei im Rahmen der vorliegenden Arbeit zunächst einmal das Augenmerk auf die gemeinsame ästhetische Dimension all solcher Bilder gelenkt, die aus ihrer zeitlichen und multimodalen Inszenierungs- und Artikulationsform hervorgeht. ${ }^{150}$ Darauf also, dass es „die reale Zeit der sinnlichen Wahrnehmungsprozesse des Zuschauers, der Prozeß der Semiose selbst [ist], der in dieser Art der Darstellung auf eine Weise gestaltet und modelliert wird, wie man es sonst nur aus der Musik kennt““. 151

So geht die Theorie filmischer Expressivität davon aus, dass in der Wahrnehmung audiovisueller Bilder, d. h. im Filme-Sehen, die affektive Dimension eines Fühlens - eine Empfindungsbewegung - und die kognitive Dimension eines Verstehens - eine Denkbewegung - nicht voneinander ablösbar sind. Von einem Prozess der Semiose zu sprechen, meint hier immer, dass das, was es bei Filmen zu verstehen gibt, an ihre je spezifische ästhetische Organisation von Wahrnehmung gebunden ist. Filmische Bilder verweisen also weniger auf etwas ihnen Vorgängiges, als dass sie vielmehr ihren Sinn, ihre Bedeutung aus sich selbst heraus entfalten. Emphatisch findet sich dieser Gedanke einer filmimmanenten, affektgebundenen Bedeutung etwa bei Merleau-Ponty:

Der Sinn des Films ist mit seinem Rhythmus verschmolzen, wie der Sinn einer Geste der Geste unmittelbar ablesbar ist, und der Film will nichts bedeuten außer sich selbst. Die Idee ist hier in den Geburtszustand rückversetzt, sie taucht auf aus der zeitlichen Struktur des Films wie in einem Tableau aus der Koexistenz seiner Teile. Das Glück der Kunst ist zu zeigen, wie etwas eine Bedeutung anzunehmen beginnt, und zwar nicht durch Anspielung auf bereits entwickelte und erworbenen Ideen, sondern durch die zeitliche oder räumliche Anordnung der Elemente. ${ }^{152}$

Ohne, dass auf kausallogische Operationen abgehoben würde, greift auch hier die Auffassung der kognitiven Filmtheorie, dass für audiovisuelle Bilder kein Kommunikationsmodell greift, „welches Bedeutung als etwas versteht, das

Geschichte - Analyse. Hrsg. v. Ralf Adelmann, Jan O. Hesse, Judith Keilbach, Markus Stauff und Matthias Thiele. Konstanz: UVK 2001, S. 125-164).

150 Vgl. auch Scherer/Greifenstein/Kappelhoff: Expressive Movements in Audiovisual Media, S. 2089.

151 Kappelhoff: Matrix der Gefühle, S. 153, Herv. CS.

152 Merleau-Ponty: Das Kino und die neue Psychologie, S. 81. 
stromaufwärts“ - etwa durch einen Regisseur - „zu Wasser gelassen wird, um vom Zuschauer herausgeangelt zu werden“. ${ }^{153}$ Indem der Wahrnehmungsakt des Zuschauers immer schon mit dem audiovisuellen Wahrnehmungsakt verschränkt und synchronisiert zu denken ist, impliziert die Idee filmischer Expressivität eine für das meaning-making konstruktive Zuschaueraktivität, die vom audiovisuellen Bild modelliert wird. Fluchtlinie, so ließe sich mit Sobchack sagen, ist „an existentially grounded and radical semiotics and hermeneutics capable of describing the origins of cinematic intelligibility and the signifying activity of embodied vision“. ${ }^{154}$ Das Schauen eines Films erscheint in einer solchen Perspektive, die die grundlegend verkörperte Dimension audiovisueller Bilder unterstreicht, als Partizipation, als Teilhabe an einem „materielle[n] Ereignis“. ${ }^{155}$ In theoretischer Hinsicht sind Filme, wie im Rückgriff auf Eisenstein argumentiert wird, „weder als Texte, ${ }^{156}$ noch als narrative Strukturen, noch als Repräsentationen von Handlungen, Geschichten oder Bildern“ aufzufassen, sondern vielmehr als

Aggregate, die eine bestimmte Art und Weise des Wahrnehmens, Empfindens und Verstehens als Zuschauererfahrung installieren, vorstrukturieren, ermöglichen. Sie sind als apriorische Struktur zu verstehen, die einen spezifischen Modus des Sehens und Hörens, des Empfindens und Denkens begründet. Und sie setzen dieses Wahrnehmen, Fühlen und Denken als ästhetische Erfahrung im Raum des Kinos in Szene. ${ }^{157}$

Dabei setzt ein in der filmischen Expressivität verankertes Semiosekonzept einer handlungsbezogenen Kausallogik eine jeweils spezifische und auf das dynamische Ganze des jeweiligen Films bezogene Relationslogik entgegen. Es geht um

eine eigene Logik der Verknüpfungen, eine spezifische Bewegung der Semiose, mit der sie ein immanent wirksames, nur diesem Film eigenes Zeichenregime entfaltet. In diese ,innere Bewegung des kinematographischen Bilds, seiner Entfaltung in der Dimension der Zeit, sind alle Ebenen kinematographischer Darstellung eingebunden: die Ebene des abbildlich Repräsentierten (Handlung, Figuren, das Schiff) ${ }^{158}$ so gut wie die Ebene der reinen Formelemente des optisch-akustischen Bilds (der Licht- und Farbgebung, der Raumbildung, der

153 Bordwell: Kognition und Verstehen, S. 22.

154 Sobchack: The Address of the Eye, S. xvii.

155 Zechner: Die Sinne im Kino, S. 225.

156 Wie oben dargelegt, ist es eben eine solche Text-Auffassung audiovisueller Bilder, die zwar implizit, dennoch besonders prominent in Forcevilles Position zum Tragen kommt (vgl. Kapitel 3 der vorliegenden Arbeit).

157 Kappelhoff: Die Anschaulichkeit des Sozialen und die Utopie Film, S. $315 \mathrm{f}$.

158 Kappelhoff formuliert diesen Gedanken mit Blick auf seine Analyse von James Camerons TITANIC (USA 1997). 
Bewegungsformationen, Sound) und die Ebene der tradierten Ikonographien und vorgeformten Handlungstopoi. ${ }^{159}$

Obgleich abbildlich Repräsentiertes (man kann auch vom gegenständlich Dargestellten sprechen) eine Ebene des filmischen Bildes ist: Ein solches dem jeweiligen Film je eigenes Zeichenregime - hier sei der Bogen zurück zu den Ausführungen zur aisthetischen Performativität geschlagen ${ }^{160}$ - hebt, aufs Ganze betrachtet, die Idee des repräsentationalen Zeichens, d.h. die Trennung von Zeichen und Bezeichnetem auf. Denn „[w]as entsteht, ist ein Bildraum, in dem alles Sichtbare bedeutsam, aber noch die tiefsinnigste Bedeutung darstellende Oberfläche ist: [...] ein gestikulierendes Signifikat [...].“" ${ }^{161}$ Kern einer solchen Idee von Semiose, von der Genese von Bedeutung, von Prozessen des meaning-making ist demnach, dass filmische Bilder Ausdrucksgestalten sind, die Inhalt und Form integrieren - ebenso, wie sie Film und Zuschauer miteinander verschränken:

Die Semiose stellt selbst noch eine zeitliche Struktur dar, mit der das Wahrnehmen und Denken, die sinnlich-psychische und die kognitive Bewegung des Zuschauens in den Bildraum des Films eingewoben sind. Daher bezieht sich das ästhetische Verfahren nicht auf eine Textur, sondern auf eine rhythmische Strukturierung der Bewußtseinsbewegung des Zuschauers [...]. ${ }^{162}$

159 Hermann Kappelhoff: And the heart will go on and on. Untergangsphantasie und Wiederholungsstruktur in dem Film Titanic von James Cameron. In: montage AV 8.1 (1999), S. 85-108, hier S. 90f., Herv. CS.

160 Vgl. Kapitel 8.1 der vorliegenden Arbeit.

161 Kappelhoff: And the heart will go on and on, S. 102, Herv. CS.

162 Ebd., S. 105f. Deleuzes Auffassung von filmischen Bildern als einer „Zeichenmaterie“, die als dynamisches System beschrieben werden könnte, resoniert hier: eine Materie, in der Prozesse zugleich aufs Ganze als auch auf dessen Teile hin am wirken sind; eine Materie, die „sensorische (visuelle und akustische), kinetische, intensive, affektive, tonale und selbst verbale (mündliche und schriftliche) Merkmale besitzen kann“ (Deleuze: Das Zeit-Bild, S. 45); eine Materie, bei er es sich (Deleuze bezieht sich hier auf Metz’ Diskussion, ebd., S. 46) „,[s]elbst unter Berücksichtigung ihrer verbalen Elemente nicht um eine Sprache - weder langue noch language [handelt]. Vielmehr haben wir hier mit einer plastischen Masse, einer signifikantenlosen, asyntaktischen, und deswegen nicht sprachlich geformten Materie zu tun, obgleich sie keineswegs amorph, sondern semiotisch, ästhetisch und pragmatisch geformt ist.“ 